ARTICLE

DOI: $10.1038 / \mathrm{s} 41467-018-06591-6$

\title{
HIV-1 Tat interactions with cellular 7SK and viral TAR RNAs identifies dual structural mimicry
}

Vincent V. Pham¹, Carolina Salguero ${ }^{1,2}$, Shamsun Nahar Khan 1,3, Jennifer L. Meagher ${ }^{4}$, W. Clay Brown ${ }^{4}$, Nicolas Humbert ${ }^{5}$, Hugues de Rocquigny ${ }^{5,6}$, Janet L. Smith ${ }^{4,7} \&$ Victoria M. D'Souza ${ }^{1}$

The HIV Tat protein competes with the 7SK:HEXIM interaction to hijack pTEFb from 7SK snRNP and recruit it to the TAR motif on stalled viral transcripts. Here we solve structures of 7SK stemloop-1 and TAR in complex with Tat's RNA binding domain (RBD) to gain insights into this process. We find that 7SK is peppered with arginine sandwich motifs (ASM)-three classical and one with a pseudo configuration. Despite having similar RBDs, the presence of an additional arginine, R52, confers Tat the ability to remodel the pseudo configuration, required for HEXIM binding, into a classical sandwich, thus displacing HEXIM. Tat also uses R52 to remodel the TAR bulge into an ASM whose structure is identical to that of the remodeled ASM in 7SK. Together, our structures reveal a dual structural mimicry wherein viral Tat and TAR have co-opted structural motifs present in cellular HEXIM and 7SK for productive transcription of its genome.

\footnotetext{
${ }^{1}$ Department of Molecular and Cellular Biology, Harvard University, Cambridge, MA 02138, USA. ${ }^{2}$ Vice Presidency of Research, Universidad de los Andes, Bogotá 111711, Colombia. ${ }^{3}$ Department of Pharmacy, East West University, Dhaka 1212, Bangladesh. ${ }^{4}$ Life Sciences Institute, University of Michigan, 210 Washtenaw Ave, Ann Arbor, MI 48109, USA. ${ }^{5}$ Faculté de Pharmacie, Laboratoire de Bioimagerie et Pathologies, UMR 7021 du CNRS, Université de Strasbourg, 74 route du Rhin, 67401 IIIkirch, France. ${ }^{6}$ Inserm - U1259 MAVIVH. Morphogenèse et Antigénicité du VIH et des Virus des Hépatites, 10 boulevard Tonnelle - BP 3223, 37032 Tours Cedex 1, France. ${ }^{7}$ Department of Biological Chemistry, University of Michigan, Ann Arbor, MI 48109, USA. Correspondence and requests for materials should be addressed to V.M.D'S. (email: dsouza@mcb.harvard.edu)
} 
T he transition from initiation to elongation during transcription of the integrated HIV genome is critical for expression of the viral mRNA ${ }^{1-7}$. Similar to many cellular genes, RNA polymerase II is able to initiate transcription of the HIV genome but is inhibited soon after by negative elongation factors $^{8-11}$. To relieve this repressed state, stalled polymerases require phosphorylation by the cellular positive elongation factor, $\mathrm{pTEFb}^{2}$. However, the availability of pTEFb is tightly regulated and is kept sequestered in an inactive state by the 7SK small nuclear ribonucleoprotein (7SK snRNP) with the help of the HEXIM adapter protein ${ }^{1,2,4,6,12}$ (Fig. 1a). To activate elongation, HIV has evolved the viral Tat protein, whose RBD directly interacts with the 7SK snRNA to displace HEXIM and capture $\mathrm{pTEFb}^{13,14}$. Tat then transfers pTEFb as part of a larger super elongation complex to the viral genome ${ }^{15-17}$. This handover occurs via the interaction of Tat with the stem loop structure, TAR, which forms at the 5' end of stalled nascent HIV transcripts. The formation of the pTEFb:Tat:TAR ternary complex positions $\mathrm{pTEFb}$ in close proximity to the polymerase, thus stimulating elongation ${ }^{5}$. The mechanistic process by which the same Tat RBD is able to engage with both the cellular 7SK and its viral counterpart TAR has thus far remained elusive.

In vivo truncation studies have shown that of the four stem loops in 7SK snRNA, only the first stem-loop is required for Tat interaction, which has been mapped to the upper portion of stemloop $1\left(\mathrm{G}_{24}\right.$ to $\mathrm{C}_{87}$; 7SK-SL1 ${ }^{\text {apical }}$, Fig. $\left.1 \mathrm{~b}\right)$ with the remainder of the 7SK RNA being dispensable ${ }^{14,18,19}$. Mutational studies have also shown that the direct Tat:7SK RNA interaction does not require Tat's pTEFb-binding capacity, but is solely dependent on Tat's RNA-binding activity, which is attributed to its RNA binding-domain (RBD, G48-R57) ${ }^{14}$. Furthermore, studies have shown that, like Tat, HEXIM interacts with the same apical portion of the stem-loop 1 in 7SK, with the displacement of HEXIM occurring by direct interaction of Tat with the 7SK snRNA ${ }^{14,19}$. Due to their remarkably similar RBD sequences ${ }^{13}$, it has been proposed that Tat has evolved to mimic HEXIM, thus potentially providing a basis for HEXIM displacement.

While there are no structures detailing how Tat RBD binds TAR, on the basis of biophysical studies, it is clear that the hallmark of this interaction is the formation of an arginine sandwich motif (ASM) when an arginine in Tat's RBD intercalates into the bulge region of $\mathrm{TAR}^{20-25}$. Specifically, in this motif, nucleotides are arranged in a sandwich-like manner to form stacking interactions with the guanidinium moiety of an arginine: the cap of the motif is formed by a bulge pyrimidine involved in a triple interaction with the stem, while the base of the motif is formed by the nucleotide involved in Watson-Crick pairing immediately preceding the bulge. While structural studies have failed to identify the arginine responsible for the formation of this motif, in vivo experiments have demonstrated arginine 52 (R52) to be the critical residue required for transactivation $^{20,25-28}$.

In this study, we provide mechanistic details of how Tat is able to first compete with HEXIM to engage 7SK for pTEFb extraction and subsequently bind TAR to transfer $\mathrm{pTEFb}$.

\section{Results}

Structure of the free 7SK-SL1 1 apical. We first performed binding studies using Tat RBD (G44-Q60) with 7SK-SL1 ${ }^{\text {apical }}$ engineered to have a GNRA-type tetraloop in order to prevent aggregation at concentrations needed for solution state biophysical studies. Nuclear Magnetic Resonance (NMR) analysis shows that the various motifs of this construct (described below) are retained despite substitution of the loop (Supplementary Fig. 1a). Additionally, Tat binding studies using isothermal calorimetry titration (ITC) revealed high-affinity and specific binding traces for both the native loop and GNRA tetraloop constructs $\left(K_{\mathrm{d}}=\right.$ $51.8 \pm 0.7 \mathrm{nM}$ and $32.2 \pm 3.5 \mathrm{nM}$, respectively; Fig. 1c, Supplementary Table 2). To ensure that we were capturing biologically relevant events, we also comparatively studied binding with fulllength Tat in the context of the CycT1:Tat:AFF4 complex. This complex binds both the native loop and GNRA tetraloop constructs with comparable affinities $\left(K_{\mathrm{d}}=55.3 \pm 12.5 \mathrm{nM}\right.$ and 44.7 $\pm 15.4 \mathrm{nM}$, respectively; Fig. 1c, Supplementary Table 2), indicating that the loop is not critical for RBD binding. Importantly, the affinities of Tat RBD and CycT1:Tat:AFF4 complex are similar, confirming the 7SK-SL1 stem region and Tat RBD to be the primary contributors of the 7SK-snRNA:Tat interaction ${ }^{13,14,18}$.

Initial characterization by NMR showed that the folding of the 7SK-SL1 ${ }^{\text {apical }}$ stem is sensitive to the concentration of salt ions, potentially due to the presence of many bulges interspersed in close proximity within a short stretch of RNA (Fig. 1b). We used Tat RBD binding as a direct readout for correct folding of the RNA. While divalent ions do not have a noticeable effect, low concentrations of monovalent salt $(<70 \mathrm{mM} \mathrm{NaCl})$ give rise to non-specific binding of Tat RBD to 7SK-SL1 1 apical (Supplementary Fig. 1b). In stark contrast, tight and specific binding of Tat RBD only occurs when $\mathrm{NaCl}$ concentrations are greater than $70 \mathrm{mM}$. This observation is corroborated by our NMR studies where the RBDs bind in a saturable manner and gives rise to distinct chemical shifts in the slow exchange regime only under ideal monovalent ion concentrations.

Free 7SK-SL1 ${ }^{\text {apical }}$ is a largely linear molecule with four pyrimidine-rich bulges within one helical turn of the RNA stem (Fig. 1d and Table 1; for details of NMR data used to solve the structure, see Supplementary Discussion). Interestingly, all of these bulges $\left(\mathrm{C}_{75} \mathrm{U}_{76}, \mathrm{C}_{71} \mathrm{U}_{72}, \mathrm{U}_{40} \mathrm{U}_{41}\right.$, and $\left.\mathrm{U}_{63}\right)$ engage in tertiary interactions that either form or have the potential to form arginine sandwich motifs. The $\mathrm{C}_{75} \mathrm{U}_{76}, \mathrm{C}_{71} \mathrm{U}_{72}$, and $\mathrm{U}_{63}$ bulges form classical arginine sandwich motifs $\mathrm{ASM}_{1}, \mathrm{ASM}_{2}$, and $\mathrm{ASM}_{4}$, respectively (Fig. 1e, f). Several unambiguous base-ribose NOE (nuclear Overhauser effect) contacts show that residues $\mathrm{C}_{75}, \mathrm{C}_{71}$, and $\mathrm{U}_{63}$ engage in triple interactions with base pairs in the stem $\left(\mathrm{G}_{78}-\mathrm{C}_{33}, \mathrm{G}_{74}-\mathrm{C}_{35}\right.$, and $\mathrm{A}_{65}-\mathrm{U}_{44}$, respectively) to form the caps of the sandwiches. On the other hand, residues $\mathrm{G}_{74}, \mathrm{G}_{70}$, and $\mathrm{C}_{62}$ of the Watson-Crick pairs that precede these caps form the bases of the sandwiches (Fig. 1d-f and Supplementary Figs 2-4, and Supplementary Discussion).

In stark contrast, the $\mathrm{U}_{40} \mathrm{U}_{41}$ bulge forms a pseudo-arginine sandwich motif (pseudo- $\mathrm{ASM}_{3}$ ) with a unique structural architecture wherein the sandwich cap is preformed but the sandwich base is sequestered. Specifically, $U_{40}$ forms a conventional cap by engaging with $\mathrm{A}_{43}-\mathrm{U}_{66}$ to form a triple interaction. However, intense NOE connectivities from both the $\mathrm{H}^{\prime}{ }^{\prime}$ and $\mathrm{H} 8$ protons of the preceding $\mathrm{A}_{39}$ to the $\mathrm{H} 3$ proton of $\mathrm{U}_{68}$ show that $\mathrm{A}_{39}$ is sequestered in a reverse Hoogsteen interaction (Supplementary Fig. 2). This orients the $A_{39}$ purine ring towards the minor groove and precludes it from forming the conventional base of an ASM (Fig. 1e). Out of the four motifs present in free 7SK-SL1 ${ }^{\text {apical }}$, only the pseudo- $\mathrm{ASM}_{3}$ has a unique architecture. As this is the only ASM where the sandwich base is not part of a G-C Watson-Crick pair, we mutated the reverse Hoogsteen $\mathrm{A}_{39}{ }^{\circ} \mathrm{U}_{68}$ pair to a $\mathrm{G}_{39}-\mathrm{C}_{68}$ pair $\left(\mathrm{A}_{39} \mathrm{G}, \mathrm{U}_{68} \mathrm{C}\right)$. This change allowed the motif to take on a completely preformed characteristic like the other ASMs, confirming that sequestration of the sandwich base in pseudo- $\mathrm{ASM}_{3}$ is caused by the presence of an $\mathrm{A}^{\circ} \mathrm{U}$ pair preceding the bulge (Supplementary Fig. 5a).

The orientation of the individual motifs gives rise to two structural entities based on their relative proximities. First, $\mathrm{ASM}_{1}$ 
a

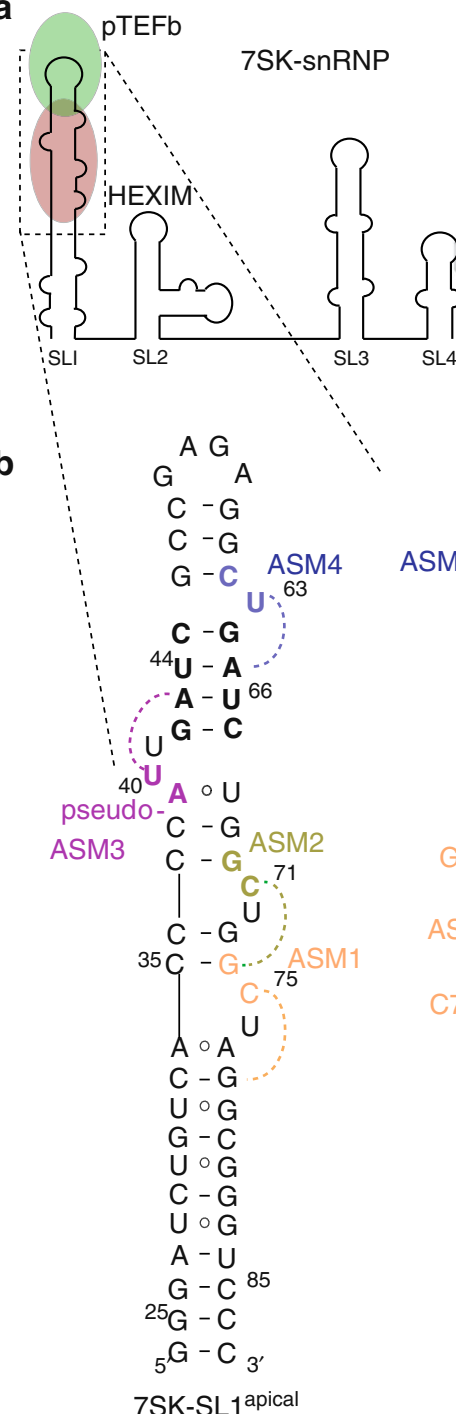

d

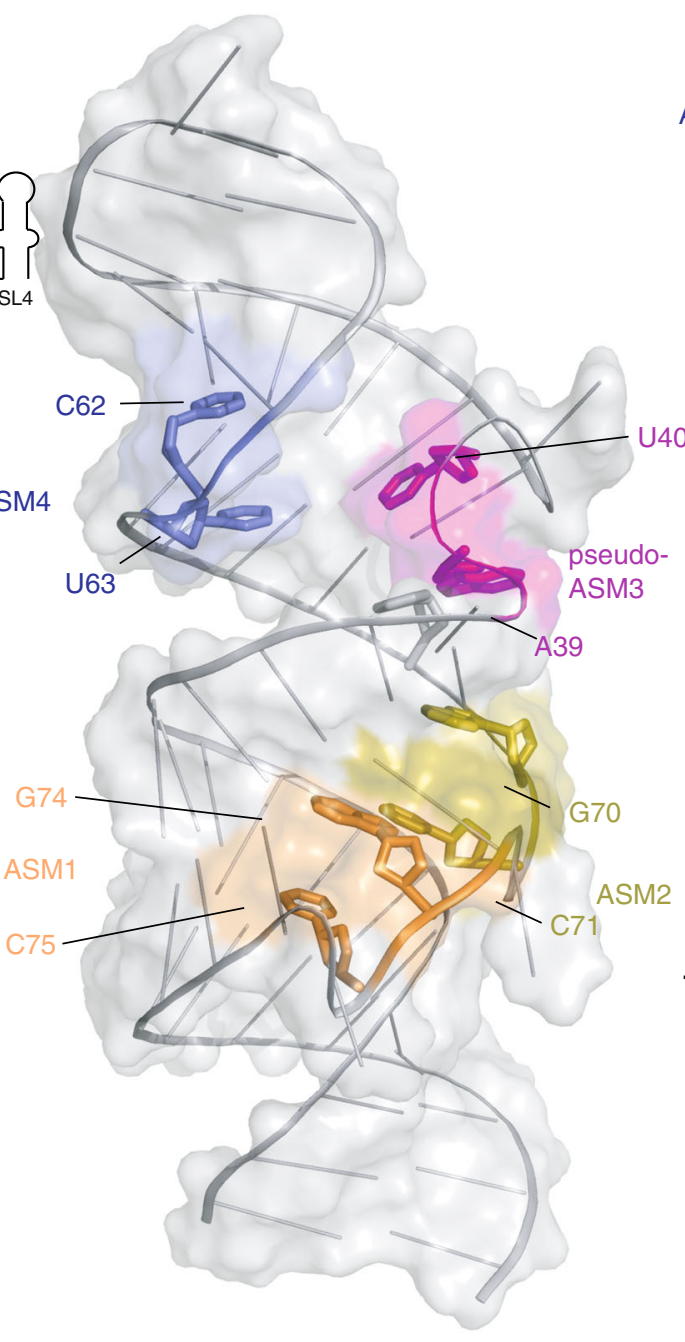

e

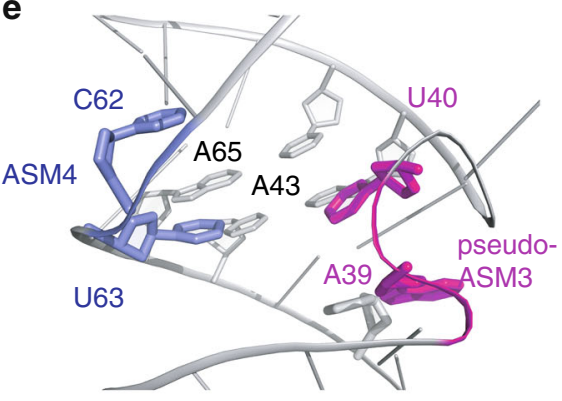

U68
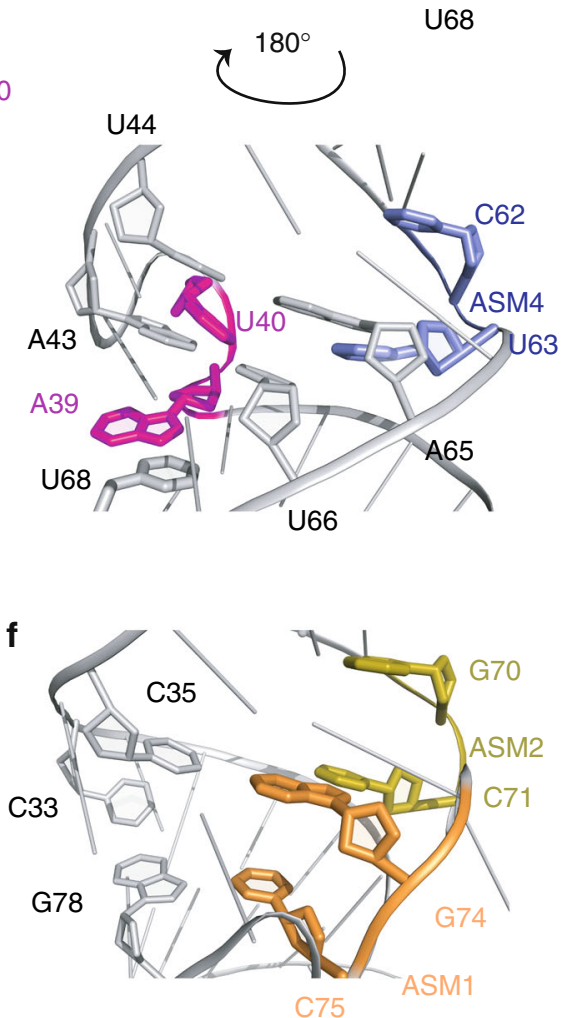

C
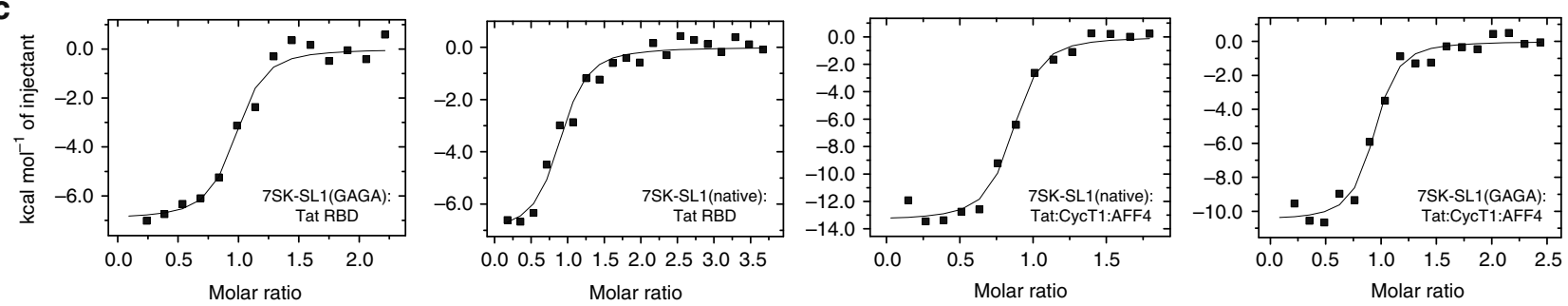

Fig. 1 Structure and characterization of free 7SK-SL1apical. a Cartoon representation of pTEFb and HEXIM binding to 7SK-SL1 in 7SK snRNP. b Secondary structure of 7SK-SL1apical with the base and cap residues forming $\mathrm{ASM}_{1}, \mathrm{ASM}_{2}$, pseudo-ASM $\mathrm{A}_{3}$ and $\mathrm{ASM}_{4}$ colored in orange, olive, magenta, and blue, respectively. The dashed arcs represent the triple-base interactions from the bulge to the stem, giving rise to the roofs of the sandwiches. Nucleotides in bolded black represent the four palindromic base pairs involved in pseudo-ASM 3 and ASM $_{4}$ formation. c Representative ITC data for Tat RBD and Tat: CycT1:AFF4 binding to 7SK-SL1apical with a GNRA or native loop, which show Tat RBD-mediated interactions are preserved in the larger complex. The continuous lines represent the fit for a one-site binding model. $\mathbf{d}$ NMR structure of the free 7SK-SL1apical RNA with color schemes matching the secondary structure in $\mathbf{b}$. e $180^{\circ}$ rotated views of the apical, near-symmetric pseudo- $A_{S M}$ and $A_{S M}$ shows residues $U_{40}$ and $U_{63}$ forming triple bases with consecutive stem base pairs and $A_{39}$ sequestered in a reverse Hoogsteen base pair. $\mathbf{f}$ View of the tandem $A_{S M}$ and $A_{S M} M_{2}$ shows that $G_{74}$ is involved in the formation of both sandwiching motifs

and $\mathrm{ASM}_{2}$ are oriented in tandem on the same strand in the lower part of the stem loop. Both of these ASMs share residue $\mathrm{G}_{74}$ to form overlapping sandwiches. Specifically, the $C_{75}$ cap of $A_{S M}$ is engaged in a typical $\mathrm{C}_{75}: \mathrm{G}_{78}-\mathrm{C}_{33}$ triple interaction, and residue
$\mathrm{G}_{74}$ forms the base of the sandwich; however, $\mathrm{G}_{74}$ also simultaneously engages the protonated $C_{71}$ cap of $\mathrm{ASM}_{2}$ in a $\mathrm{C}_{71}{ }^{+}: \mathrm{G}_{74}-\mathrm{C}_{35}$ triple-base interaction (Fig. If and Supplementary Figs. 2, 3). Second, the pseudo-ASM 3 and $\mathrm{ASM}_{4}$ are arranged on 
Table 1 NMR statistics and restraints for 7SK-SL1apical, 7SK-SL1apical:Tat RBD, and Tat RBD:TAR

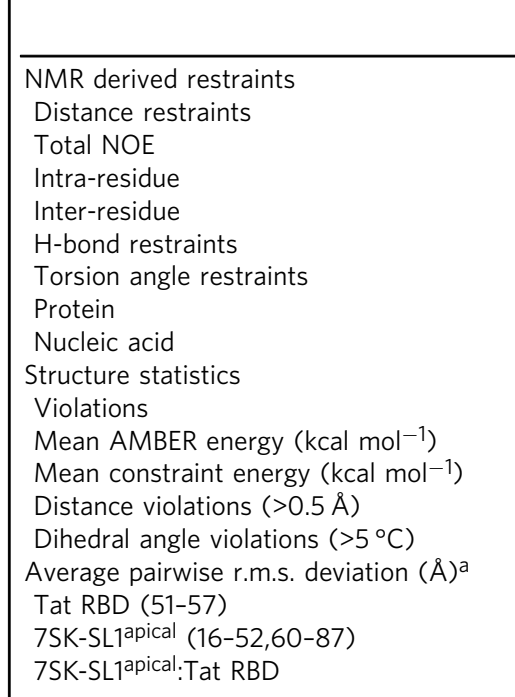

7SK-SL1

(CYANA) (AMBER)

7SK-SL1:Tat RBD (CYANA)

7SK-SL1 Tat RBD $\quad$ Complex

$\begin{array}{lllll}727 & 556 & 806 & 33 & 807 \\ 421 & 251 & 430 & - & 430 \\ 175 & 175 & 213 & 1 & 214 \\ 131 & 130 & 163 & 32 & 163 \\ 696 & - & 692 & 314 & 1006 \\ - & - & - & 314 & 314 \\ 696 & - & 692 & - & 692\end{array}$

$\begin{array}{ll}- & -13,661.40 \\ - & 18.95 \\ - & 0 \\ - & 0 \\ - & - \\ - & 0.47 \pm 0.10 \\ - & -\end{array}$

7SK-SL1:Tat RBD (AMBER)

\begin{tabular}{lll}
\hline 7SK-SL1 & Tat RBD & Complex
\end{tabular}

\section{TAR:Tat RBD (CYANA)}

632
260
209
163
-
-
-

33
-
1
32
-
-
-

633
260
210
163
-
-
-

633

260

210

163

$-$

$-$

\begin{tabular}{|c|c|c|c|c|c|c|}
\hline & \multicolumn{3}{|c|}{ TAR:Tat RBD (CYANA) } & \multicolumn{3}{|c|}{ TAR:Tat RBD (AMBER) } \\
\hline & TAR & Tat RBD & Complex & TAR & Tat RBD & Complex \\
\hline \multicolumn{7}{|l|}{ NMR derived restraints } \\
\hline \multicolumn{7}{|l|}{ Distance restraints } \\
\hline Total NOE & 425 & 30 & 425 & 335 & 30 & 335 \\
\hline Intra-residue & 234 & - & 234 & 144 & - & 144 \\
\hline Inter-residue & 96 & 5 & 96 & 96 & 5 & 96 \\
\hline H-bond restraints & 95 & 25 & 95 & 95 & 25 & 95 \\
\hline Torsion angle restraints & 373 & 315 & 688 & - & - & - \\
\hline Protein & - & 315 & 315 & - & - & - \\
\hline Nucleic acid & 373 & - & 373 & - & - & - \\
\hline RDC Restraints & - & - & 11 & - & - & 11 \\
\hline \multicolumn{7}{|l|}{ Structure statistics } \\
\hline \multicolumn{7}{|l|}{ Violations } \\
\hline Mean AMBER energy $\left(\mathrm{kcal}^{\mathrm{mol}}{ }^{-1}\right)$ & - & & & -8675 & & \\
\hline Mean constraint energy ( $\left.\mathrm{kcal} \mathrm{mol}{ }^{-1}\right)$ & - & & & 36.26 & & \\
\hline Distance violations $(>0.5 \AA)$ & - & & & 0 & & \\
\hline Dihedral angle violations $\left(>5^{\circ} \mathrm{C}\right)$ & - & & & 0 & & \\
\hline RDC violations $(>0 \mathrm{~Hz})$ & & & & 0 & & \\
\hline \multicolumn{7}{|l|}{ Average pairwise r.m.s. deviation $(\AA)^{a}$} \\
\hline Tat RBD $(49-54)$ & - & $0.91 \pm 0.30$ & & & & \\
\hline TAR RNA (16-46) & - & $0.54 \pm 0.25$ & & & & \\
\hline TAR:Tat RBD & - & $0.84 \pm 0.19$ & & & & \\
\hline
\end{tabular}

opposite strands with a near-symmetrical architecture (Fig. 1e). The sandwich caps of the pseudo- $\mathrm{ASM}_{3}\left(\mathrm{U}_{40}\right)$ and $\mathrm{ASM}_{4}\left(\mathrm{U}_{63}\right)$ form symmetrical triple interactions with palindromic base pairs in the stem $\left(\mathrm{U}_{40}: \mathrm{A}_{43}-\mathrm{U}_{66}\right.$, and $\mathrm{U}_{63}: \mathrm{A}_{65}-\mathrm{U}_{44}$, respectively). Hence, despite being four base pairs apart in the secondary structure, this architecture arranges them as consecutive triple bases. Indeed, this close spatial proximity of the cap residues $\mathrm{U}_{40}$ and $\mathrm{U}_{63}$ is evidenced by connectivities between their $\mathrm{H} 3$ protons (Supplementary Fig. 2a, b). On the other hand, the arrangement of the sandwich bases prevents the formation of a truly symmetrical unit due to the differential geometries of the reverse Hoogsteen and Watson-Crick pairing in pseudo- $\mathrm{ASM}_{3}$ and $\mathrm{ASM}_{4}$, respectively (Fig. 1e). Overall, these distinct structural units present 7SK with two different platforms for arginine interaction: a pair of tandem motifs provides two adjacent preformed cavities, while the other spatially opposed, partially-symmetric pair provides one preformed cavity and one sequestered motif.

Engagement of 7SK-SL1 ${ }^{\text {apical }}$ by Tat's RBD. To investigate how the full-length Tat RBD utilizes the various arginine-sandwich motifs in 7SK, we performed structural analyses by SAXS and NMR. The reconstructed $\mathrm{ab}$ initio SAXS envelope shows that there are no major rearrangements in the global architecture of the 7SK-SL1 ${ }^{\text {apical }}$ upon protein binding (Fig. $2 \mathrm{a}$ ). Indeed, while we observe numerous intermolecular NOEs from all motifs, no major changes in NOE connectivities that define the preformed sandwiches themselves were observed, proving that the overall structural integrity is maintained (Fig. $2 \mathrm{~b}$ and Table 1, 
a

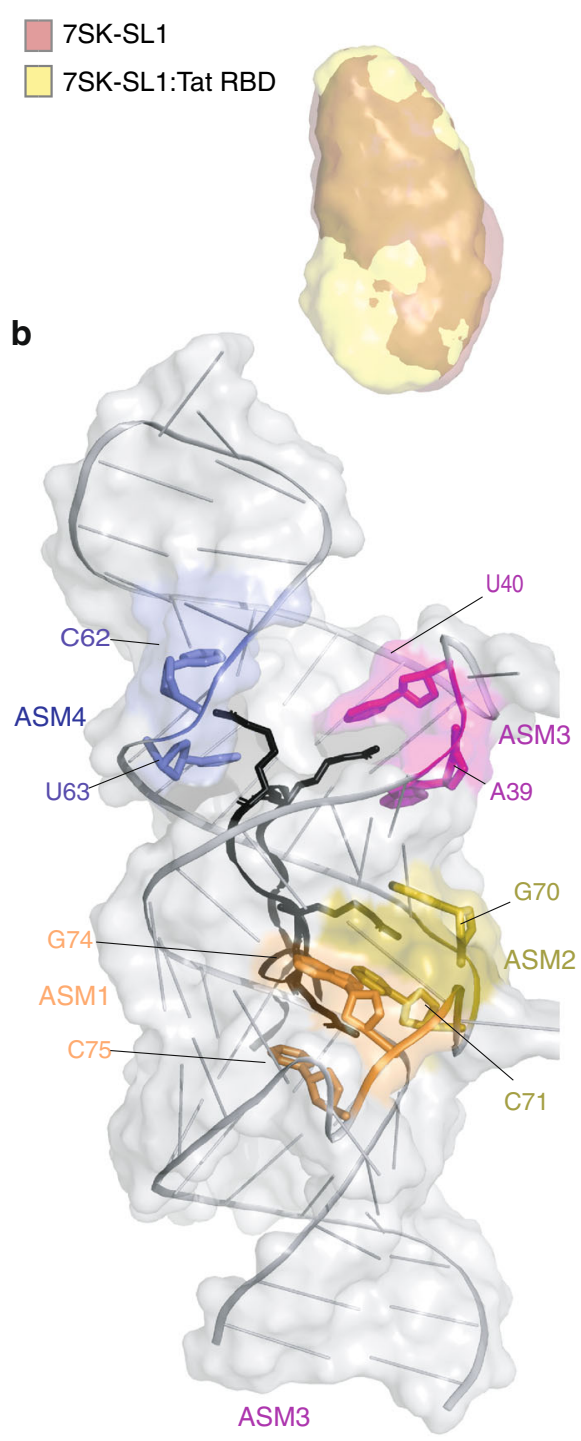

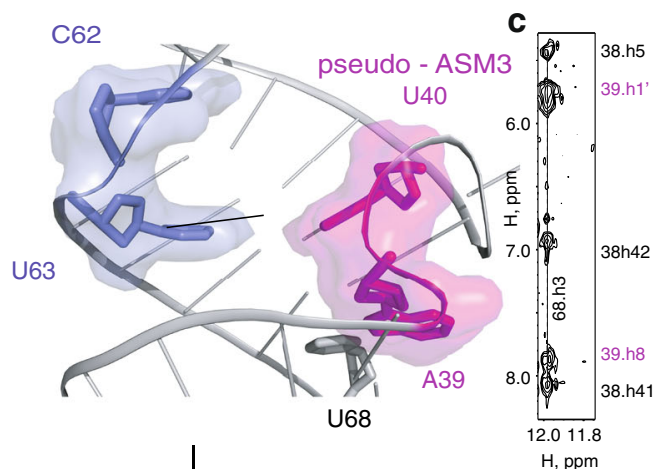
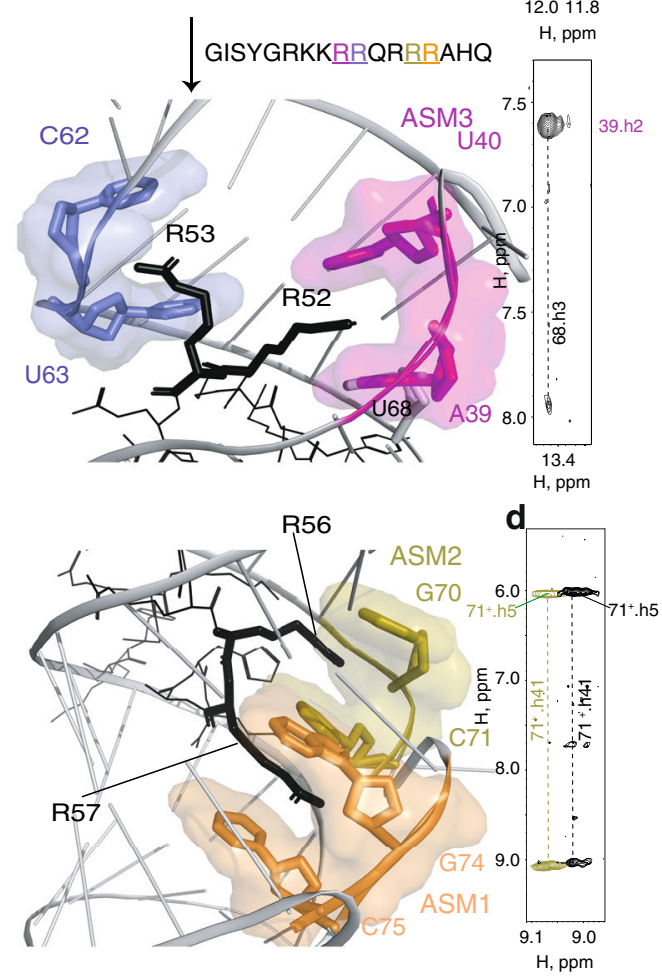

Fig. 2 Structure and characterization of Tat RBD bound to 7SK-SL1 ${ }^{\text {apical }}$. a Overlay of reconstructed ab initio SAXS envelope of free 7SK-SL1 ${ }^{\text {aaical }}$ (coral) and the 7SK-SL1apical:Tat RBD complex (yellow) demonstrating the lack of global rearrangement of the RNA. b NMR structure of 7SK-SL1apical bound to Tat RBD (black), showing multiple arginines intercalating into the ASMs. Arginine residues in the Tat RBD primary sequence are color-coded to match the respective ASMs that they intercalate into. Top and middle insets: R52 induces the formation of $\mathrm{ASM}_{3}$ from the pseudo-ASM $\mathrm{A}_{3}$ configuration, while R53 interacts with the preformed $\mathrm{ASM}_{4}$. Bottom inset: interaction of the tandem $\mathrm{ASM}_{1}$ and $\mathrm{ASM}_{2}$ with $\mathrm{R} 57$ and R56, respectively. ${ }^{1} \mathrm{H}-{ }^{1} \mathrm{H}$ two- dimensional NOESY showing transition of $A_{39}-U_{68}$ from a reverse Hoogsteen interaction to a Watson-Crick interaction by the appearance of the characteristic $U_{68}$ imino to $\mathrm{A}_{39} \mathrm{H} 2$ upon titration of Tat. $\mathbf{d}$ Spectral overlay showing that $\mathrm{ASM}_{2}$ remains intact after Tat intercalation as evidenced by the maintenance of the downfield shifted amino of the protonated cap $\mathrm{C}_{71}{ }^{+}$. Black, free 7SK-SL1apical and olive, after titration with 1.0 equivalent of Tat RBD

See Supplementary Discussion). Most perturbations occur in pseudo- $\mathrm{ASM}_{3}$. In particular, the $\mathrm{A}_{39} \mathrm{H} 2$ proton experiences a dramatic upfield chemical shift from 6.77 to $6.49 \mathrm{ppm}$ and gives rise to an intense $\mathrm{NOE}$ connectivity to the $\mathrm{U}_{68} \mathrm{H} 3$ imino proton characteristic of a Watson-Crick base pair formation between the two residues (Fig. 2c). Thus, upon Tat RBD binding, the $\mathrm{A}_{39}{ }^{\circ} \mathrm{U}_{68}$ reverse Hoogsteen becomes a Watson-Crick base pair, converting the pseudo into a classical arginine sandwich motif $\left(\mathrm{ASM}_{3}\right)$ to give rise to a truly symmetrical arrangement of $\mathrm{ASM}_{3}$ and $\mathrm{ASM}_{4}$ that results in four fully-formed ASMs (Fig. 2c).

The structure shows that residues K51-R57 of Tat RBD engage 7SK-SL1 apical. Although the arginine sandwich motifs are dispersed throughout an entire helical turn of the RNA, this eight-amino acid stretch is able to engage all four ASMs, potentially due to the multiple points of arginine intercalations into the major groove from the start to the end of the helical turn (Supplementary Discussion). To position the various arginines into the correct arginine sandwich motifs, we used Tat RBD with various combinations of specifically labeled amino acids (Supplementary Fig. 5b). An unambiguous set of intermolecular NOEs places R57, R56, R52, and R53 into $A_{1} M_{1}$ through $A_{S M}$, respectively (Supplementary Fig. 6). The arginine side chains are precisely anchored by intermolecular NOEs between the arginine side chain protons with the aromatic $\mathrm{H} 5 / \mathrm{H} 6$ protons of the sandwich caps. For example, R53 and R52 $\mathrm{H} \beta$ and $\mathrm{H} \gamma$ protons gave strong NOE connectivities to the $\mathrm{U}_{63}$ and $\mathrm{U}_{40} \mathrm{H} 5$ protons, respectively (Fig. 3a and Supplementary Fig. 6a, b). We also observe guanidinium nitrogen moieties from all labeled arginines 

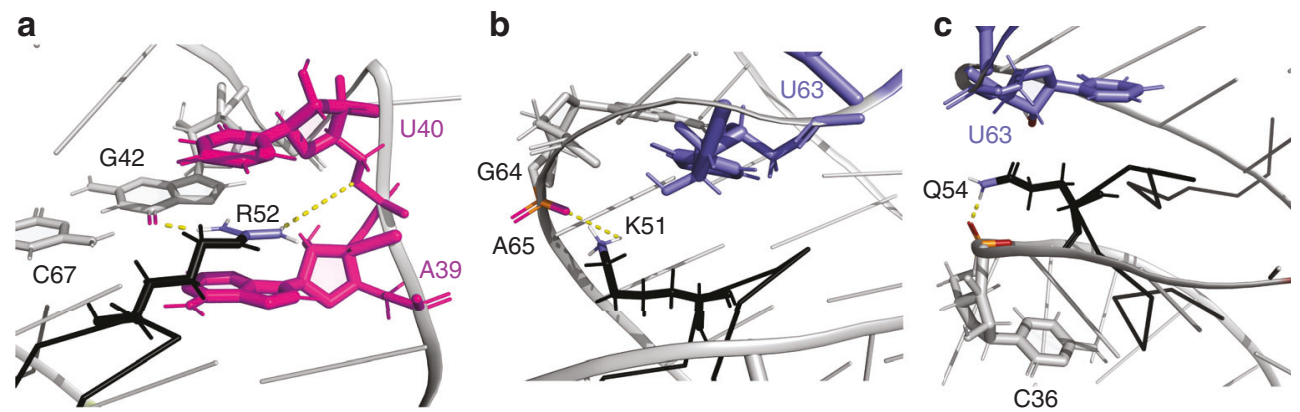

Fig. 3 Intermolecular interactions between Tat RBD and 7SK-SL1apical. Close-up view of a the ASM 3 binding pocket showing residues $\mathrm{G}_{42}$ (gray), $\mathrm{A}_{39}$ and $\mathrm{U}_{40}$ (magenta), and R52 (black). The dotted lines indicate hydrogen bond interactions from the two N groups of arginine 52 to the $\mathrm{O}_{6}$ of $\mathrm{G}_{42}$ and the $\mathrm{O} 5^{\prime}$ of $\mathrm{U}_{40}$; $\mathbf{b}$ the K51 interaction as Tat RBD exits the major groove. The dotted lines show the close distance of the side chain amino group of K51 to the phosphate of $A_{65}$, showing the potential to form a hydrogen bond; $\mathbf{c}$ the interaction of the spacer residue Q54 within the major groove that places it under the $\mathrm{U}_{63}$ cap residue

after complex formation, indicating the slow-exchange of these $\mathrm{H} \eta$ protons due to their involvement in hydrogen-bonding interactions within the sandwiches (Supplementary Fig. 5b).

Both the tandem and the symmetric cavities accommodate consecutive arginines. Since the tandem $\mathrm{ASM}_{1}$ and $\mathrm{ASM}_{2}$ stack on the same strand, it allows the C-terminal arginines R57 and R56 to dock into these motifs in a ladder-like configuration (Fig. 2b, Supplementary Fig. 6c). This occurs without any significant changes in the organization of these ASMs (Fig. 2d). Tat RBD then continues its course through the major groove and docks the N-terminal arginine $\mathrm{R} 52$ into $\mathrm{ASM}_{3}$ (Fig. 2b). However, the preceding arginine residue $\mathrm{R} 53$ flips upward to interact with $\mathrm{ASM}_{4}$, causing the chain to reverse its direction and exit the RNA through the same groove as the $\mathrm{C}$ - terminus. This inverse intercalation of $\mathrm{R} 52$ and $\mathrm{R} 53$ into the symmetrical $\mathrm{ASM}_{3}$ and $\mathrm{ASM}_{4}$ creates a distinct fork-like arrangement of the two arginines (Fig. 2b). The reversal of the chain also leads to the formation of a short $\beta$-hairpin encompassing residues $\mathrm{K} 51$ to Q54. Intermolecular connectivities between $\mathrm{K} 51 \mathrm{H \varepsilon}$ and the $\mathrm{H} 8$ of $\mathrm{A}_{65}$ support this reversal and places the side-chain amino group of K51 within hydrogen bonding distance of the $A_{65}$ phosphate backbone (Fig. 3b and Supplementary Fig. 6d). Q54 and $\mathrm{R} 55$ serve as spacer residues that bridge the distance between the symmetrical and tandem motifs, allowing the N-terminal and C-terminal arginines to intercalate into these motifs, respectively. This is evidenced by connectivities from $\mathrm{R} 55 \mathrm{H} \delta$ to $\mathrm{H} 5 / \mathrm{H} 6$ of $\mathrm{C}_{35}$ and $\mathrm{Q} 54 \mathrm{H} \beta$ to the $\mathrm{H} 2^{\prime}$ of the $\mathrm{U}_{63}$ roof, placing Q54 directly under $\mathrm{ASM}_{4}$ (Fig. 3c and Supplementary Fig. 6a). Taken together, our structures show how the highly conserved arginine-rich sequence intimately docks deep into the major groove using all four arginine sandwiches as anchoring points.

To understand the contributions of each ASM in 7SK-SL1 ${ }^{\text {apical }}$ for Tat binding, we designed constructs to individually disrupt the formation of each of the ASMs $\left(\mathrm{ASM}_{1} \mathrm{U} 76 \mathrm{~A}, \mathrm{ASM}_{2} \mathrm{U72A}\right.$, $\mathrm{ASM}_{3} \mathrm{U} 40 \mathrm{~A}$, and $\left.\mathrm{ASM}_{4}{ }^{\mathrm{DU} 63}\right)$. These mutations not only successfully abrogate the intended ASM, but also do not significantly affect the integrity of the other ASMs (Supplementary Figs. 7, 8a). Binding analysis via ITC shows that while TatRBD binds $\mathrm{ASM}_{1}{ }^{\mathrm{U} 76 \mathrm{~A}}, \mathrm{ASM}_{2}{ }^{\mathrm{U} 72 \mathrm{~A}}$, and $\mathrm{ASM}_{4}{ }^{\Delta \mathrm{U} 63}$ with a ten-fold, threefold and thirteen-fold decreased affinity $\left(K_{\mathrm{d}}=308.7 \pm 30.2 \mathrm{nM}\right.$, $86.8 \pm 34.9 \mathrm{nM}$, and $428.3 \pm 221.4 \mathrm{nM}$ ), respectively (Supplementary Fig. 8b, Supplementary Table 2), binding of Tat-RBD to the $\mathrm{ASM}_{3} \mathrm{U} 40 \mathrm{~A}$ construct is completely abolished (Supplementary Fig. 8c). These data are consistent with in vivo work, which show that deletions in the $\mathrm{ASM}_{1}, \mathrm{ASM}_{2}$ region, and a deletion of $\mathrm{U}_{63}$ in $\mathrm{ASM}_{4}$ are tolerated, but a single mutation at the $\mathrm{U}_{40}$ position is detrimental for Tat binding ${ }^{14}$.
Mechanism of HEXIM displacement by Tat. To gain a mechanistic understanding of how Tat displaces HEXIM, we performed biochemical and structural studies with HEXIM RBD (K149-R156). The binding affinity of HEXIM for 7SK-SL1 ${ }^{\text {apical }}$ is two-fold weaker in comparison to Tat $\left(K_{\mathrm{d}}=66.6 \pm 9.0 \mathrm{nM}\right.$ and $32.2 \pm 3.5 \mathrm{nM}$, respectively; Fig. 1c, Fig. 4a, Supplementary Table 2), although both have similar modes of binding in that they are both enthalpically and entropically favorable $(\Delta \mathrm{H}=$ $-5.9 \pm 1.5$ and $-7.9 \pm 1.7 \mathrm{kcal} \mathrm{mol}^{-1}$ and $-\mathrm{T} \Delta \mathrm{S}=-4.33 \pm 1.4$ and $-1.95 \pm 1.5 \mathrm{kcal} \mathrm{mol}^{-1}$, respectively). Binding experiments of the native 7SK-SL1 ${ }^{\text {apical }}$ loop to HEXIM and Tat also show that the difference in binding affinities is maintained in the native loop context $\left(K_{\mathrm{d}}=80.0 \pm 1.8 \mathrm{nM}\right.$ and $55.3 \pm 12.5 \mathrm{nM}$, respectively; Figs. 1c, 4a, Supplementary Table 2).

Next, we performed competition experiments by NMR. We began by titrating HEXIM RBD into 7SK-SL1 ${ }^{\text {apical }}$ in the NMR to understand HEXIM's mode of binding. While HEXIM's RBD is able to engage the preformed motifs, no signature $A_{39} \mathrm{H} 2$ chemical shift indicative of $\mathrm{ASM}_{3}$ formation is observed, even upon adding five-fold excess of HEXIM RBD (Fig. 4b). We then performed a direct competition assay by titrating Tat RBD into this HEXIM RBD:7SK-SL1 ${ }^{\text {apical }}$ complex in order to visualize any structural changes that occur. Addition of Tat's RBD causes the emergence of the upfield-shifted $\mathrm{A}_{39} \mathrm{H} 2$ proton at $6.49 \mathrm{ppm}$, showing that Tat RBD is able to outcompete HEXIM and bind 7SK-SL1 1 apical (Fig. 4b). On the other hand, titration of HEXIM RBD into a 7SK-SL1 ${ }^{\text {apical:Tat }}$ complex does not result in the reversal of the $\mathrm{A}_{39} \mathrm{H} 2$ proton chemical shift, indicating that HEXIM is unable to effectively compete with Tat RBD (Fig. 4b).

Since the transition from pseudo- $\mathrm{ASM}_{3}$ to $\mathrm{ASM}_{3}$ accompanies HEXIM displacement and represents the only major change in 7SK induced by R52 upon Tat encounter, we wanted to understand the interplay between $\mathrm{R} 52$ and $\mathrm{ASM}_{3}$, which allows for both HEXIM displacement and Tat binding to 7SK. In vivo data shows that like Tat, HEXIM binding is critically dependent on the pseudo- $\mathrm{ASM}_{3}$ region as even minor changes to residues in this region completely abolishes HEXIM recognition ${ }^{13,14,19}$. Indeed, while titration of HEXIM RBD into 7SK-SL1 ${ }^{\text {apical }}$ gives rise to high affinity binding, titration into the $\mathrm{ASM}_{3} \mathrm{U} 40 \mathrm{~A}$ construct, like Tat, leads to no heats of binding (Fig. 4a, c). Since the same RNA region is important for both Tat and HEXIM binding and this bulge can adopt both a pseudo- and a classical ASM configuration, we then wanted to test if there are any predetermined requirements that specify either Tat or HEXIM RBD binding. To accomplish this, we used the $\mathrm{A}_{39} \mathrm{G}$, $\mathrm{U}_{68} \mathrm{C}$ construct where the pseudo- $\mathrm{ASM}_{3}$ was engineered to force the formation of a fully-formed, classical $\mathrm{ASM}_{3}$. While Tat RBD 

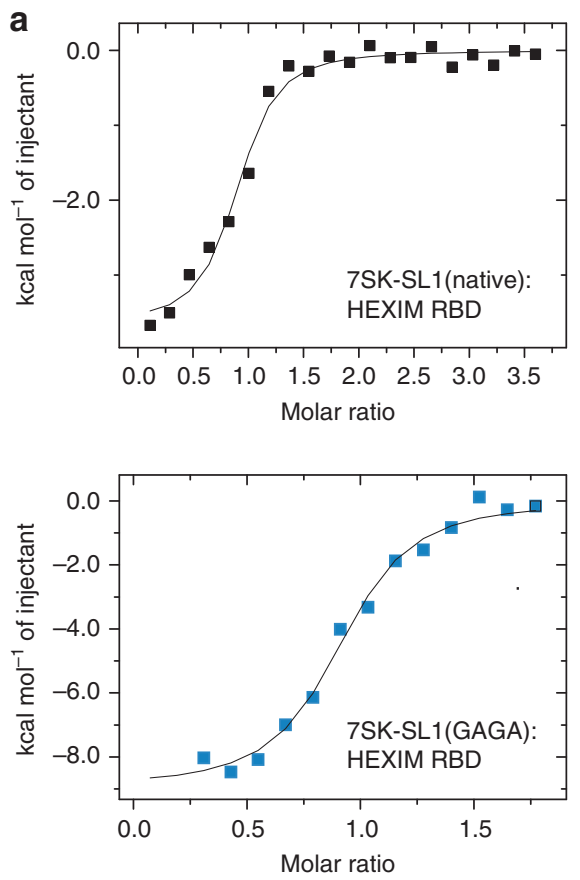

b
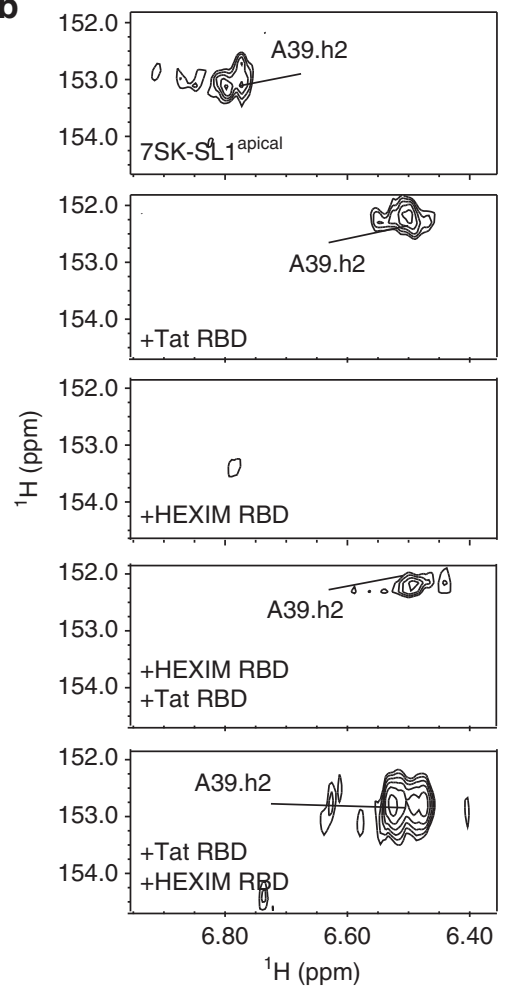
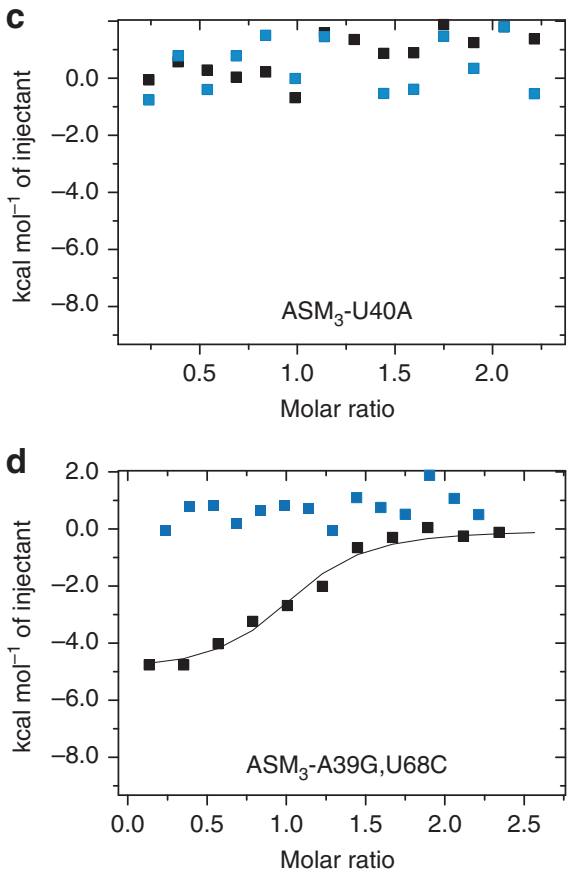

Fig. 4 The role of R52 in HEXIM displacement. a Representative ITC data for HEXIM RBD binding to both 7SK-SL1apical both with the native (top) and GAGA tetraloop (bottom). A continuous line represents the fit for one-site binding model. $\mathbf{b}$ HMQC spectra of free 7SK-SL1apical (top panel). Titration of 1 equivalent of Tat RBD leads a characteristic upfield shift in the $A_{39} \mathrm{H} 2$ proton indicative of the $A_{39}-U_{68}$ Watson-Crick base-pair formation (second panel). On the other hand, titration of five equivalents of HEXIM RBD did not lead to such a shift (third panel). Titration of 1 equivalent of Tat RBD into this HEXIM:7SK complex led to the emergence of the upfield $A_{39}$ chemical shift characteristic of that of Tat:7SK-SL1apical, indicating HEXIM displacement (fourth panel). On the other hand, titration of 1 equivalent of HEXIM RBD into a Tat:7SK-SL1 ${ }^{\text {apical }}$ complex with 2 equivalents of Tat RBD did not lead to the loss of the upfield-shifted $\mathrm{A}_{39} \mathrm{H} 2$ proton shift, indicting lack of Tat displacement by HEXIM (bottom panel). c Representative ITC data for both HEXIM RBD (blue) and Tat RBD (black) binding to the $U_{40} A$ mutant, which disrupts the formation of pseudo- $A_{S M}$. Both constructs gave no heats of binding. d Representative ITC data for titration of both HEXIM (blue) and Tat (black) RBDs into the $A_{39} G, U_{68} C$ construct that causes a preformed $A S M M_{3}$. While Tat RBD was able to engage this motif, HEXIM RBD gave no heats of binding

binds this construct, albeit with a five-fold decrease in affinity compared to the wild-type $\left(K_{\mathrm{d}}=140.5 \pm 30.9 \mathrm{nM}\right)$, HEXIM RBD binding was abolished (Fig. $4 \mathrm{~d}$, Supplementary Table 2), showing that classical sandwich formation and HEXIM binding are mutually exclusive. Furthermore, R52K is also unable to bind the preformed $\mathrm{ASM}_{3}$ construct with specificity, showing that a lysine at this position prohibits both the R52K mutant Tat and HEXIM from appropriately engaging a classical $\mathrm{ASM}_{3}$ (Supplementary Fig. 8d,e). Taken together, these data indicate that the ability of Tat to switch the pseudo- $\mathrm{ASM}_{3}$ into a classical sandwich due to a single additional arginine provides Tat a competitive advantage for displacing HEXIM.

To understand the importance of arginine intercalations for HEXIM displacement, we mutated individual intercalating arginines to alanines. While the data for R53A binding was uninterpretable due to severe line-broadening of NMR signals, studies with the R57A, R56A, and R52A mutant constructs show that interactions of individual arginines occur independently of the neighboring ASM (Supplementary Fig. 8f). These constructs are also able to compete with HEXIM for binding to 7SK-SL1 1 apical, albeit with reduced affinity. Concomitant with binding, both R56A and $\mathrm{R} 57 \mathrm{~A}$ are able to induce the transition of $\mathrm{ASM}_{3}$ from pseudo to classical while R52A is unable to do so (Supplementary Fig. 9). Our structures show R52 to be responsible for the classical sandwich formation, and since it also represents the only conserved substitution from K151 in HEXIM $\left(\mathrm{KR}_{52} \mathrm{RQRRR}\right.$ in
Tat vs. $\mathrm{KK}_{151}$ KHRRR in HEXIM) ${ }^{13}$, we studied the reciprocal Tat R52K and HEXIM K151R mutations. While these 7SK-SL1 ${ }^{\text {apical }}$ complexes are able to engage the tandem ASMs $\left(\mathrm{ASM}_{1}\right.$ and $\mathrm{ASM}_{2}$ ), their interactions with the symmetrical motifs $\left(\mathrm{ASM}_{3}\right.$ and $\mathrm{ASM}_{4}$ ) were dynamic (Supplementary Fig. 9). The HEXIM K151R construct is able to remodel the pseudo configuration and is not completely displaced from 7 SK-SL1 ${ }^{\text {apical }}$ upon encountering native Tat RBD (Supplementary Fig. 9). Furthermore, the R52K complex reveals that unlike the R52A mutation, R53 can compensate for the remodeling of $\mathrm{ASM}_{3}$ in the absence of R52, indicating that the local environment of the RBD encountering the pseudo- $\mathrm{ASM}_{3}$ dictates the ability to adapt and remodel this motif (Supplementary Fig. 8f). This compensatory role in inducing the switch leads to complete displacement of HEXIM upon titration of R52K into a HEXIM:7SK-SL1 ${ }^{\text {apical }}$ complex (Supplementary Fig. 9). These studies show the advantage of having multiple intercalation points, which allows for plasticity both in the mode of binding to 7SK-SL1 ${ }^{\text {apical }}$ and for HEXIM displacement.

Engagement of TAR by Tat's RBD. Similar to 7SK-SL1 $1^{\text {apical }}$, our ITC experiments show high affinity binding of both the Tat RBD and the CycT1:Tat:AFF4 complex to TAR $\left(K_{\mathrm{d}}=22.5 \pm 15.2 \mathrm{nM}\right.$ and $77.7 \pm 62.7 \mathrm{nM}$, respectively), confirming previous studies that the Tat RBD significantly contributes to the interaction with TAR RNA (Fig. 5a, b, Supplementary Table 2) ${ }^{23,29,30}$. We also confirmed that the CycT1:Tat:AFF4 complex is able to engage the 
a

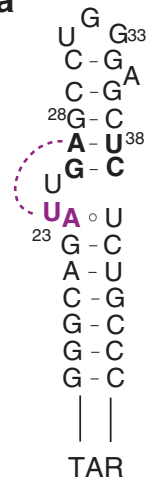

b

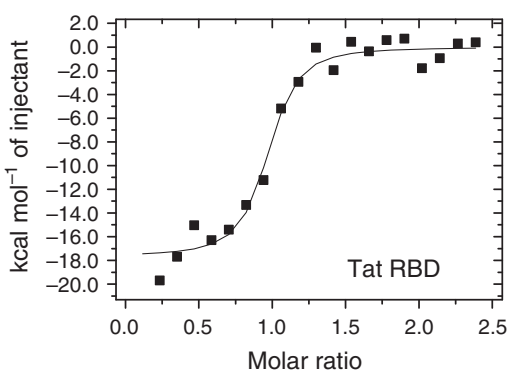

c
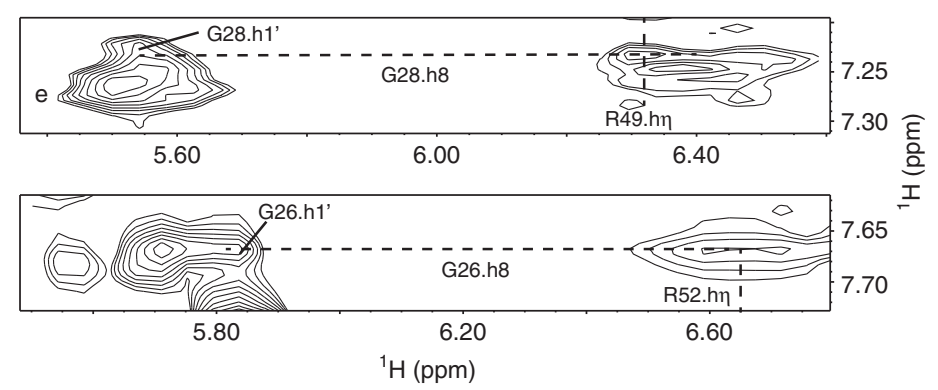

e

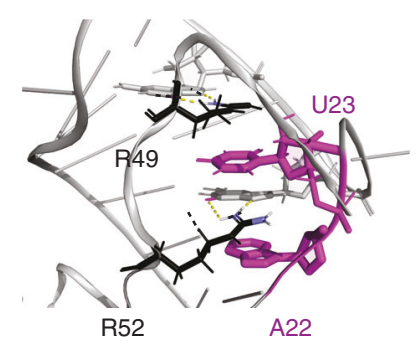

f

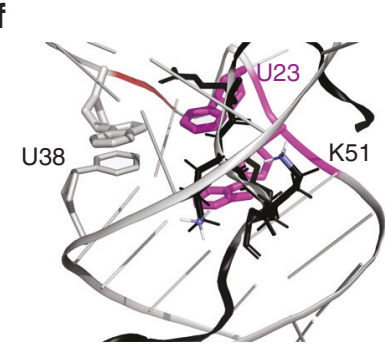

g

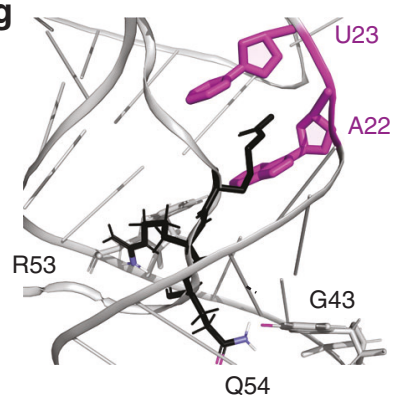

Fig. 5 Structure and characterization Tat RBD in complex with TAR. a Secondary structure of TAR where the dashed arcs represent the triple-base interactions between $U_{23}$ from the bulge to the $A_{27}-U_{38}$ base pair in the stem, giving rise to the roof of the sandwich. $\mathbf{b}$ Representative ITC data of Tat RBD (left) and the Tat:CycT1:AFF4 (right) titration into TAR RNA, respectively. Continuous lines represent the fit for a one-site binding model. $\mathbf{c}^{1} \mathrm{H}-{ }^{1} \mathrm{H}$ twodimensional NOESY showing the NOEs between the R49 and R52 hn guanidinium protons and $\mathrm{G}_{28}$ and $\mathrm{G}_{26} \mathrm{H} 8$ protons, respectively, placing these residues in an arginine fork interaction. $\mathbf{d}$ NMR structure of TAR bound to Tat RBD (black) showing R49 and R52 sandwiching the $U_{23}$ cap of the ASM sandwich. e The ASM binding pocket with the $A_{22}$ base and the $U_{23}$ cap (magenta), $G_{26}$ and $G_{28}$ (gray), and R49 and R52 (black). The dotted lines indicate hydrogen bond interactions from the $\mathrm{NH}$ group of arginine 49 and 52 to the $\mathrm{O} 6$ and $\mathrm{N7}$ of $\mathrm{G}_{28}$ and $\mathrm{G}_{26}$, respectively. $\mathbf{f}$ Positions of K50 and $\mathrm{K} 51$ (black) in the major groove. $\mathbf{g}$ The R53 and Q54 interaction with $\mathrm{U} 40$ and G43, respectively. Close proximity of the R538 to the $\mathrm{C}_{39}, \mathrm{U}_{40}$, and $\mathrm{C}_{41} \mathrm{H} 5$ protons evidenced by the data and a dotted line represents the potential hydrogen bonding interaction between a guanidinium proton of R53 to the $\mathrm{U}_{40}$ phosphate. The hydrogen bond interaction between the Q54 he proton and the $\mathrm{G}_{43} \mathrm{O} 6$ represents the C-terminal exit of Tat RBD from TAR

TAR loop in the same manner as previous established (Supplementary Fig. 10a $)^{31}$. To make structure-based comparisons between 7SK-SL1 ${ }^{\text {apical }}$ and TAR, we solved the structure of Tat RBD:TAR complex under the same salt conditions used to solve the Tat RBD: 7SK-SL1 ${ }^{\text {apical }}$ complex.
As predicted from previous work, titration of Tat RBD into TAR results in the formation of an arginine sandwich motif $22,23,32: U_{23}$ of the bulge makes a triple-base interaction with $A_{27}-U_{38}$ base pair in the stem to form the cap of the sandwich while the preceding $A_{22}$ forms the base of the sandwich 
(Supplementary Fig. 10b). It is interesting to note that the secondary structures of the TAR bulge and 7SK-SL1 ${ }^{\text {apical }} \mathrm{ASM}_{3}$ are identical. While Tat RBD binding eventually does give rise to identical tertiary arginine sandwich structures, the free structures are significantly different. Unlike the pseudo- $\mathrm{ASM}_{3}$ configuration in 7SK where the base triple is preformed, the TAR bulge is flexible and adopts multiple conformations. We rationalized that this stark difference must arise due to effects from neighboring motifs: whereas in 7SK-SL1 ${ }^{\text {apical }}$ the pseudo-ASM ${ }_{3}$ triple base is in close proximity to a structured $\mathrm{ASM}_{4}$, in TAR, the preformed triple base would be in close proximity to the dynamic apical hexaloop ${ }^{33}$. Indeed, substitution of the TAR hexaloop with a GNRA motif allows the bulge to take on the pseudo-ASM configuration, indicating that the apical loop has a destabilizing effect on the bulge (Supplementary Fig. 10c).

Upon Tat RBD binding, this apical loop is stabilized by the formation of a $\mathrm{C}_{30}-\mathrm{G}_{34}$ base-pair, thus giving rise to the predicted pseudo-triloop configuration (Supplementary Fig. 10b) ${ }^{34-36} \cdot \mathrm{G}_{26}$ though $\mathrm{U}_{31}$ show NOEs representative of classical stacking interactions, after which there is a strand reversal with $G_{32}$ and $\mathrm{G}_{33}$ oriented towards the minor groove face of the molecule. The strand then continues with $G_{34}$ stacking onto $G_{36}$ and with $A_{35}$ flipped out of the stem, positioning the base towards the minor groove as evidenced by only a weak $\mathrm{A}_{35} \mathrm{H} 2$ connectivity to the $\mathrm{G}_{36} \mathrm{H1}^{\prime}$ (Supplementary Fig. 11).

The structure of the TAR:Tat RBD complex shows that Tat RBD enters the major groove of TAR near the stem-pentaloop junction, as evidenced by a network of NOEs from the $\mathrm{G}_{28}-\mathrm{C}_{37}$ basepair and the closing pentaloop base, $\mathrm{G}_{34}$, to the $\mathrm{N}$-terminal $\mathrm{R} 49$. Briefly, the $\mathrm{R} 49 \mathrm{H} \beta$ and $\mathrm{H} \gamma$ protons are in close proximity to $\mathrm{G}_{34} \mathrm{H} 8$, whereas the $\mathrm{R} 49 \mathrm{H} \delta$ protons are near the $\mathrm{C}_{37} \mathrm{H} 5$ proton (Supplementary Fig. 12a-c). Additionally, R49 makes hydrogenbonding interactions via the guanidinium moiety with the base of $\mathrm{G}_{28}$ as evidenced by the $\mathrm{G}_{28} \mathrm{H} 8 \mathrm{NOE}$ to the $\mathrm{R} 49 \mathrm{H \eta}$ protons, thus positioning it over the remodeled TAR bulge (Fig. $5 \mathrm{c}-\mathrm{e}$ ). Like 7SK-SL1 ${ }^{\text {apical }}$, the remodeling of the TAR bulge also occurs via intercalation of arginine 52 into the sandwich motif. The guanidinium moiety makes hydrogen-bonding interactions with $\mathrm{G}_{26}$ and we observe intermolecular NOEs from the aromatic protons of the $U_{23}$ cap and the $A_{22}$ base to the $H \gamma$ and $H \delta$ protons of R52 (Fig. 5c-e and Supplementary Fig. 12a, b). Thus, the Tat:TAR interaction is stabilized by both R49 and R52, which stack over and under the cap residue $U_{23}$, respectively (Supplementary Fig. 12b).

The intervening residues $\mathrm{K} 50$ and $\mathrm{K} 51$ are also shown to be involved in stabilizing the Tat-TAR bulge interaction. For example, we observe NOEs from the $\mathrm{H} 5$ protons of both $\mathrm{C}_{37}$ and $\mathrm{U}_{38}$ to the $\mathrm{K} 50 \mathrm{He}$ proton (Fig. $5 \mathrm{f}$ and Supplementary Fig. 12a), as well as NOEs from the $\mathrm{H} 8$ protons of $\mathrm{G}_{36}$ and $\mathrm{G}_{34}$ to the $\mathrm{K} 51 \mathrm{H} \varepsilon$ proton. Below the bulge, the Tat RBD and TAR interaction continues with $\mathrm{R} 53$ and Q54, both of which are oriented within the major groove. The $\mathrm{R} 53$ sidechain protons are in close proximity to the $\mathrm{H} 5$ protons of $\mathrm{C}_{39}, \mathrm{U}_{40}$, and $\mathrm{C}_{41}$ (Fig. $5 \mathrm{~g}$ and Supplementary Fig. 12c), orienting the guanidinium moiety of $\mathrm{R} 53$ within hydrogen bonding distance of the $\mathrm{U}_{40}$ backbone. Finally, the Q54 $\mathrm{N} \varepsilon$ protons make hydrogen-bonding interactions with the $\mathrm{C}_{19}-\mathrm{G}_{43}$ base-pair (Fig. $5 \mathrm{~g}$ and Supplementary Fig. 12d). As the N-terminal and C-terminal residues G44-G48 and R55Q60, respectively, do not make contact with the RNA, the Tat RBD interaction is tightly contained within a short six-amino acid (R49-Q54) stretch.

\section{Discussion}

In summary, our lab has discovered that the cellular 7SK RNA7SK-SL1 $1^{\text {apical }}$ (this study) and 7 SK-SL4 ${ }^{21}$-is peppered with
ASMs previously thought to be exclusive to retroviral TAR RNA (HIV-1, HIV-2, and BIV) $22,29,37$. The structure of the Tat RBD:7SK-SL1 1 apical complex shows that the Tat RBD is able to snake through an entire helical turn of the major groove due to the multiple points of arginine intercalations that allow for numerous stacking and hydrogen-bonding interactions. Even in rare examples of protein-RNA complexes that engage the major groove, such as bovine immunodeficiency virus (BIV) Tat-TAR and HIV-1 Rev-RRE complexes, these interactions occur only within half a helical turn $22,31,38$.

We also show that HIV Tat has adapted its RBD sequence to complement the orientation and placement of arginines into the four sandwiches of 7SK. Specifically, the $\mathrm{N}$-terminal arginine pair, 52 and 53, interacts with the symmetrical $\mathrm{ASM}_{3}$ and $\mathrm{ASM}_{4}$ motifs while the C-terminal arginine pair, 56 and 57, interacts with the tandem $\mathrm{ASM}_{1}$ and $\mathrm{ASM}_{2}$ motifs. The same R52 responsible for switching the pseudo- $\mathrm{ASM}_{3}$ configuration to $\mathrm{ASM}_{3}$ for HEXIM displacement is also important for remodeling the TAR bulge into an analogous ASM with R49 making an additional stacking interaction above this induced ASM similar to that seen in the BIV Tat RBD:TAR interaction ${ }^{22}$. In 7SK, R49, and K50 do not form any contacts but are available for a potential TAR interaction. It is possible that these residues help facilitate the transfer of Tat RBD from 7SK to TAR, as seen in a recently modeled Tat RBD-TAR structure where R49 was placed outside the RNA ${ }^{31}$. Mutations in residues K50, K51, R52, R53 have been shown to have defects in HIV transactivation $17,26,27,39,40$, which these studies attribute to be due to disruption of Tat-TAR interaction. However, our studies show that Tat RBD uses many of the same residues to also bind 7SK, which in fact precedes TAR binding, necessitating a reevaluating of these conclusions.

The importance of the four arginines that intercalate into 7SK is highlighted by the fact that in a virus where mutations are a frequent occurrence with Tat being one of the highly variable proteins ${ }^{41}$, these arginines remain highly conserved (>92\% conservation frequency in HIV-1 subtype B). Despite this, studies have shown that mutations to the RBDs are fairly well tolerated $^{26,42}$. Our studies provide an explanation for this observation. We show that alanine substitutions of R57, R56, and R52 can still bind 7SK by intercalation of other ASMs. While R57 and R56 are able to remodel $7 \mathrm{SK}$, the $\mathrm{R} 52 \mathrm{~A}$ mutation loses this capability. Nevertheless, it can still access pTEFb by virtue of its ability to bind 7SK via arginine intercalation into the other ASMs. An R52K mutant allows Tat to use R53 to induce the $\mathrm{ASM}_{3}$ conformational switch and efficiently displace HEXIM, indicating that Tat RBD can be adaptable depending on the local environment of the residues encountering pseudo- $\mathrm{ASM}_{3}$. Taken together, our studies show that having the ability to switch the pseudo$\mathrm{ASM}_{3}$ allows for active displacement of HEXIM by acquisition of a comparatively higher affinity interaction for 7SK rather than a passive, probabilistic competition between HEXIM and Tat. However, the latter option is still a viable mechanism to capture pTEFb and explains why it is not possible to completely abrogate HEXIM displacement for $\mathrm{pTEFb}$ capture, even upon mutations of the critical R52 insofar as the RBD is able to enter into the major groove. In keeping with this, in vitro competition experiments performed in a fully reconstituted system show that mutations of $\mathrm{R} 52$ and $\mathrm{R} 53$ to alanine results in a reduction, rather than ablation of $\mathrm{pTEFb}$ capture and may explain why the RBD of Tat can be replaced by the RBD of BIV despite having different arginine arrangements $20,26,42,43$. It is worth noting, however, that even if mutations were made to the entire RBD in vivo, Tat is still capable of accessing pTEFb from small complexes of pTEFb:Brd 44 Finally, while our work highlights the plasticity built into HEXIM displacement, our studies shows the lack of such redundancies in the TAR-Tat system, with the sole R52 intercalating into a single 
TAR ASM. This may explain why mutations in R52 exhibit a significant reduction in transactivation despite active HEXIM displacement ${ }^{20,27}$.

Importantly, our data details the mechanistic basis for the molecular mimicry by HIV at both the protein and RNA level. At the protein level, mimicry between HEXIM and Tat RBDs allows Tat to outcompete HEXIM. Tat's RBD displays a similar overall architecture to HEXIM's RBD but with one additional arginine (R52) compared to HEXIM. In fact, in many HIV strains, R52 represents the only conserved amino acid substitution compared to a lysine at that position in HEXIM (for example, $\mathrm{KR}_{52} \mathrm{KHRRR}$ in HIV Finland strain) ${ }^{13}$. This limited variation between the two RBDs, which manifest as a two-fold advantage in dissociation constant for Tat, allows it to displace HEXIM in vitro. Since preforming $\mathrm{ASM}_{3}$ ablates HEXIM binding, our studies suggest that HEXIM requires a pseudo- $\mathrm{ASM}_{3}$ configuration to engage 7SK. Indeed, the reverse Hoogsteen $\mathrm{A}^{\circ} \mathrm{U}$ pair is highly conserved, suggesting that 7SK RNA has evolved to maintain a pseudo architecture in this region. By inducing the transition of this pseudo- $\mathrm{ASM}_{3}$ to a canonical sandwich by virtue of R52 intercalation, Tat is able to remodel 7SK into a configuration that is not conducive for interactions with HEXIM K151. As it is unlikely that 7SK has adapted its structure for Tat interaction, our studies suggest that HIV-1 Tat may have evolved to mimic a built-in structural switch-and-displace mechanism that allows a cellular factor(s) to displace HEXIM and extract pTEFb from 7SK for cellular transcriptional regulation. At the RNA level, HIV has evolved TAR to copy the exact secondary sequence of $\mathrm{ASM}_{3}$ in 7SK-SL1 apical. While the initial tertiary structures of this bulge are different in the two RNAs, the bound structure after engagement with the same arginine residue results in identical ASM formation. This RNA structural mimicry may allow nascent TAR to dislodge 7SK from 7SK:Tat:pTEFb to form the active TAR:Tat:pTEFb ternary complex required for transcriptional elongation of the HIV genome.

While the minimal Tat and HEXIM RBDs used in this study are able to recapitulate HEXIM displacement by Tat seen both in vitro and in vivo, it is possible that other domains present in Tat, HEXIM, pTEFb, and 7SK widely influence the thermodynamics of binding, and may even introduce cooperativity to make the displacement more efficient. Thus, further studies with fully reconstituted 7SK snRNP complexes and full-length Tat would be required for complete assessment of the competition, although the structural elements present in our minimal system are unlikely to change under such contexts.

\footnotetext{
Methods

RNA sample preparation. RNA samples used for biophysical experiments were synthesized by in vitro transcription using T7 RNA polymerase ${ }^{45}$ with either plasmid DNA or with synthetic DNA templates containing 2'-O-methylated (Integrated DNA Technologies) containing the T7 promoter and the desired sequences (see Supplementary Table 1 for template sequences). Plasmid DNA for 7SK-SL1 $1^{\text {apical }}, 7 \mathrm{SK}-\mathrm{SL} 1^{\text {bottom, }}$, and 7SK-SL1 ${ }^{\text {top }}$ contain the T7 promoter, insert, and SmaI sequence cloned in between EcoRI and BamHI restriction sites. Plasmid DNA was prepared for in vitro transcription by growing overnight a $100 \mathrm{~mL} \mathrm{LB}$ starter culture of NEB $5 a$ Competent E.coli (C29871) transformed with the plasmid. $30 \mathrm{~mL}$ of the overnight starter culture is inoculated into $3 \mathrm{~L}$ of LB media and grown for $16 \mathrm{~h}$. Cells were spun down at $4200 \mathrm{x}$ g for $30 \mathrm{~min}$ and cell pellets were purified using Qiagen Plasmid Giga Prep (12191). Purified DNA was linearized with SmaI (R0141L) overnight on a room temperature shaker and ready for in vitro transcription the next day. To ameliorate non-physiological dimerization, the apical loop of 7SK-SL1 (nucleotides 49-59) was replaced with either a GAGA tetraloop in 7SK-SL1 ${ }^{\text {apical/bottom }}$ or stable CAGUG pentaloop in 7SK-SL1 ${ }^{\text {top }}$. Template preparation using 2'-O-methylated reverse primers, used to suppress the heterogeneity at the 3 ' end of the transcripts, involved combining $15 \mu \mathrm{L}$ of both forward and reverse primers at $1 \mathrm{mM}$ stock solution with $47 \mu \mathrm{L}$ of water. The mixture was heated at $95^{\circ} \mathrm{C}$ for five minutes and cooled at room temperature for $30 \mathrm{~min}$ before assembling the in vitro transcription reaction. Samples were either unlabeled, or residue-specifically labeled with ${ }^{13} \mathrm{C} /{ }^{15} \mathrm{~N}$ - or ${ }^{2} \mathrm{H}$ (Cambridge Isotope
} Laboratories, Inc.). After transcription, RNA samples were heat denatured and purified by using urea-denaturing polyacrylamide gels. RNA samples used for dipolar coupling measurements were first dissolved in a buffer containing $10 \mathrm{mM}$ potassium phosphate, $70 \mathrm{mM} \mathrm{NaCl}$, and $0.1 \mathrm{mM}$ EDTA, pH 5.2 in $\mathrm{D}_{2} \mathrm{O}$. Following data collection without phage, the RNA samples were added to prepared Pf1 phage (Cederlane, P-200P). Pf1 phage was prepared by pelleting through centrifugation at $364637.4 \times \mathrm{g}$ for one hour at $4^{\circ} \mathrm{C}$. The pellet was resuspended in $2 \mathrm{~mL}$ of the $10 \mathrm{mM}$ potassium phosphate, $70 \mathrm{mM} \mathrm{NaCl}$, and $0.1 \mathrm{mM}$ EDTA, pH 5.2 in $\mathrm{D}_{2} \mathrm{O}$ and pelleted again. This solvent exchange was done a total of three times to remove residual $\mathrm{H}_{2} \mathrm{O}$ before being added to concentrated RNA.

RBD peptide preparation. Tat $\mathrm{RBD}$ peptides were prepared in $\mathrm{ABI}$ peptide synthesizers by solid phase using the standard fluorenylmethoxycarbonyl (Fmoc) method while the unlabeled peptides for native Tat RBD (GISYGRKKRRQRRRAHQ), native HEXIM RBD (GISYGRQLGKKKHRRRAHQ), Tat R52K RBD (GISYGRKKKRQRRRAHQ), Tat R52 A RBD (GISYGRKKARQRRRAHQ), Tat R53A RBD ('̄ISYGRKKRAQRRRAHQ), Tat R56A RBD (GISYGRKKRRQRAR-

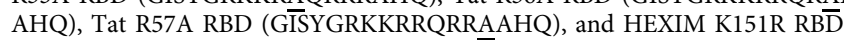
(GISYGRQLGKRKHRRRAHQ), were purchased from Tufts University Core Facility. Tat peptides containing selective ${ }^{13} \mathrm{C} /{ }^{15} \mathrm{~N}$.labeled residues, underlined, (GISYGRKKRRQRRRAHQ, GISYGRKKRRQRRRAHQ, GISYGRKKRRQRRRAHQ) were synthesized at the de Rocquigny Lab using a $0.1 \mathrm{mmol}$ scale $^{46,47}$. To incorporate selective labeled amino acids, an equimolar mixture $(0.2$ mmol) of labeled and non-labeled residues was added to the cartridge and the resulting peptides were purified by HPLC. The following labeled amino-acids were purchased from Cambridge Isotope Laboratories: L-Lysine- $\alpha-\mathrm{N}-\mathrm{Fmoc}-\varepsilon-\mathrm{N}-\mathrm{T}-\mathrm{Boc}$ $\left({ }^{13} \mathrm{C}_{6}, 99 \% ;{ }^{15} \mathrm{~N}_{2}, 99 \%\right)$ ), L-Arginine-N-Fmoc, Pbf-OH $\left({ }^{13} \mathrm{C}_{6}, 99 \% ;{ }^{15} \mathrm{~N}_{4}, 99 \%\right)$, LGlutamine-N-Fmoc, $\mathrm{N}-\gamma$-Trityl $\left({ }^{13} \mathrm{C}_{5}, 99 \% ;{ }^{15} \mathrm{~N}_{2}, 99 \%\right)$ and L-Alanine-N-Fmoc $\left({ }^{13} \mathrm{C}_{3}, 97-99 \%\right.$; $\left.{ }^{15} \mathrm{~N}, 97-99 \%\right)$.

Tat:CycT1:AFF4 preparation. One-liter volumes of High-five cells (Thermo Fisher-B85502) were seeded at $2 \times 10^{6}$ cells $/ \mathrm{ml}$ in Insect X-press media (Lonza) in 2.8 L Fernbach flasks. These were infected at an MOI of 2 with His-Tat (1-72), HisGB1- Aff (32-67) and untagged Cyclin T (1-280). The flasks were incubated at 23.5 ${ }^{\circ} \mathrm{C}$ with shaking at $140 \mathrm{rpm}$ for $72 \mathrm{~h}$. The cells were then harvested by centrifugation at $1000 \times g$ and $4{ }^{\circ} \mathrm{C}$ for $40 \mathrm{~min}$ in $1 \mathrm{~L}$ bottles. The media was decanted and the pellets were removed from the bottles with a plastic spatula and placed into Ziploc freezer bags. The pellets were stored at $-80^{\circ} \mathrm{C}$ until purification. For purification, the thawed cell pellet was resuspended in lysis buffer containing $50 \mathrm{mM}$ sodium phosphate $\mathrm{pH} 7.4,300 \mathrm{mM} \mathrm{NaCl}, 10 \%$ glycerol, $0.1 \%$ 2-mercaptoethanol and $0.1 \%$ CHAPS. Protease inhibitors and benzonase (Novagen) were added. Cells were lysed by sonication and lysate was cleared by centrifugation at $30,600 \times \mathrm{g}$ for $1 \mathrm{~h}$. The Tat/ AFF/CycT1 complex was purified by affinity chromatography with Ni-NTA resin (Qiagen). The His-tag (Tat) and His-GB1-tag (AFF) were cleaved with TEV protease. The complex was run over a second Ni-NTA column then concentrated run on a Superdex200 gel filtration column (GE Healthcare Life Sciences) in buffer containing $25 \mathrm{mM}$ HEPES pH 7.5, $200 \mathrm{mM} \mathrm{NaCl}, 1 \mathrm{mM}$ DTT and 5\% glycerol. The complex was flash frozen and stored at $-80^{\circ} \mathrm{C}$.

NMR data acquisition, resonance assignment and structural calculations. For NMR experiments, the RNA samples were dissolved in a buffer containing $10 \mathrm{mM}$ potassium phosphate, $70 \mathrm{mM} \mathrm{NaCl}$, and $0.1 \mathrm{mM}$ EDTA, pH 5.2. All NMR experiments were acquired by using Bruker 700 or $800 \mathrm{MHz}$ instruments equipped with cryogenic probes. Spectra for observing non-exchangeable protons were collected at $298 \mathrm{~K}$ in $99.96 \% \mathrm{D}_{2} \mathrm{O}$, whereas those for exchangeable protons were at 283 and $298 \mathrm{~K}$ in $10 \% \mathrm{D}_{2} \mathrm{O}$. For NOESY experiments, mixing times were set to $200 \mathrm{~ms}$. Assignments of 7SK-SL1 ${ }^{\text {apical }}$ were obtained first by transferring assignments of the 7SK-SL1 ${ }^{\text {top }}$ and 7SK-SL1 ${ }^{\text {bottom }}$ to the regions that are shared with them, and then by analyzing ${ }^{1} \mathrm{H}-{ }^{1} \mathrm{H}$ 2D NOESY spectra of fully protonated sample. For TAR samples, NOESY datasets were recorded using unlabeled and various combinations of nucleotide-specific labeled samples ${ }^{48}$. Samples for 7SK-SL1 ${ }^{\text {apical }}$ :Tat-RBD and TAR:Tat-RBD complex for structure determination were prepared at a 1:0.9 equivalents, respectively, to avoid any non-specific binding by the Tat RBD. Assignments for non-exchangeable ${ }^{1} \mathrm{H}$ and ${ }^{13} \mathrm{C}$ signals of 7SK-SL1 ${ }^{\text {apical }}$ and TAR free and in complex with Tat-RBD were obtained by analyzing two-dimensional ${ }^{1} \mathrm{H}-{ }^{1} \mathrm{H}$ NOESY recorded with non-labeled samples, two-dimensional ${ }^{13} \mathrm{C}-\mathrm{HMQC}$, and three-dimensional ${ }^{13} \mathrm{C}$-edited HMQC-NOESY spectra.

Initial structural models were generated using manually assigned restraints in CYANA $^{48,49}$. Upper-limit distance restraints of 2.7, 3.3, and 5.0 A were employed for direct NOE cross-peaks of strong, medium and weak intensities, respectively. However, for crosspeaks pairs associated with the intra-residue $\mathrm{H} 8 / 6$ to $\mathrm{H} 2$ ' and H3', upper distance limits of 4.2 and $3.2 \AA$ were employed for NOEs of medium and strong intensity, respectively ${ }^{48}$. To prevent the generation of structures with collapsed major grooves, cross-helix P-P distance restraints (with $20 \%$ weighting coefficient) were employed for A-form helical segments ${ }^{48,50}$. Standard torsion angle restraints were used for regions of A-helical geometry, allowing for $\pm 50^{\circ}$ deviations from ideality $\left(\alpha=-62^{\circ}, \beta=180^{\circ}, \gamma=48^{\circ}, \delta=83^{\circ}, \varepsilon=-152^{\circ}, \zeta=-73^{\circ}\right)$. Standard hydrogen bonding restraints with an approximately linear $\mathrm{NH}-\mathrm{N}$ and $\mathrm{NH}-\mathrm{O}$ bond distances of $1.85 \pm 0.05 \AA$ and $\mathrm{N}-\mathrm{N}$ and $\mathrm{N}-\mathrm{O}$ bond distances of $3.00 \pm 0.05 \AA$, and two lower-limit restraints per base pair (G-C base pairs: G-C4 to C-C6 $\geq 8.3 \AA$ and 
G-N9 to C-H6 $\geq 10.75 \AA \AA$; A-U basepairs: A-C4 to U-C6 $\geq 8.3 \AA$ and A-N9 to U$\mathrm{H} 6 \geq 10.75 \AA$ ) were employed in order to weakly enforce base-pair planarity $(20 \%$ weighting coefficient). The twenty best CYANA models were then used for final structure calculations in $\mathrm{AMBER}^{51}$. The refinement was carried out in 50,000 steps, where the first 12,500 steps increased the temperature from 0 to $500 \mathrm{~K}$, remained at $500 \mathrm{~K}$ over the next 32,500 steps, and then decreased to $0 \mathrm{~K}$ over the next 5000 steps. A final minimization was carried out in 8000 steps. These calculations incorporated all upper limit restraints used in CYANA but not the angle restraints. For TAR, additional tensor fitting was carried out and the above structure calculation process was repeated with the RDC restraints along with a final minimization that included 8000 steps.

Isothermal titration calorimetry. Binding constants for the interaction of 7SKSL1 ${ }^{\text {apical }}$ and TAR RNAs and their mutants with the Tat and HEXIM RBDs were measured using a ITC- 200 microcalorimeter (MicroCal). Briefly, $75 \mu \mathrm{M}$ Tat or HEXIM RBD peptides were titrated into $2 \mu \mathrm{M}$ solutions of 7 SK-SL1 ${ }^{\text {apical }}$ constructs or TAR RNA in $10 \mathrm{mM}$ sodium phosphate, $70 \mathrm{mM} \mathrm{NaCl}, 0.1 \mathrm{mM}$ EDTA, pH 5.2 at $25^{\circ} \mathrm{C}$, except when analyzing the effects of salt where the $\mathrm{NaCl}$ concentration were varied from $50-100 \mathrm{mM}$. Experiments titrating the Tat:CycT1:AFF4 complex into 7SK-SL1 ${ }^{\text {apical }}$ or TAR was carried out by titrating $49 \mu \mathrm{M}$ of protein complex into 2 $\mu \mathrm{M}$ solutions of RNA in $25 \mathrm{mM}$ HEPES pH 7.5, $200 \mathrm{mM} \mathrm{NaCl}, 1 \mathrm{mM}$ DTT and 5\% glycerol. Titration curves were analyzed using ORIGIN (OriginLab). All thermodynamic parameters are reported with $n=2$ experiments except for Tat:CycT1: AFF4 binding to 7SK-SL1 ${ }^{\text {apical (GAGA) and 7SK-SL1 }}{ }^{\text {apical (Native) where } n=3}$ experiments.

Small angle X-ray scattering. SAXS data were obtained at SIBYLS beamline of Advanced Light Source at Lawrence Berkeley National Laboratory. Measurements were performed in buffer containing $10 \mathrm{mM}$ sodium phosphate, $70 \mathrm{mM} \mathrm{NaCl}, 0.1$ $\mathrm{mM}$ EDTA, $\mathrm{pH}$ 5.2. The background scattering was subtracted from the sample scattering to obtain the scattering intensity from the solute molecules. Data from four different concentrations $(20,30,40$, and $50 \mathrm{uM})$ were compared with scattering intensities at $q=0 \AA^{-1}[\mathrm{I}(0)]$, as determined by Guinier analysis, to detect possible interparticle interactions. Data were analyzed by using ScÅtter software, and the ab initio envelope structures were reconstructed by using DAMMIF/ DAMMIN software.

\section{Data availability}

Coordinates, restraints, and structures for the final ensembles of 7SK-SL1 apical, 7SK-

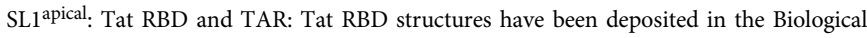
Magnetic Resonance Bank under 30512, 30511, and 30510 BMRB codes, and in the Protein Data Bank with PDB ID codes 6MCI, 6MCF, and 6MCE, respectively. All other data supporting the findings of this study are available from the authors upon request.

Received: 29 December 2017 Accepted: 11 September 2018 Published online: 15 October 2018

\section{References}

1. Nguyen, V. T., Kiss, T., Michels, A. A. \& Bensaude, O. 7SK small nuclear RNA binds to and inhibits the activity of $\mathrm{CDK} 9 /$ cyclin T complexes. Nature 414, 322-325 (2001).

2. Peterlin, B. M. \& Price, D. H. Controlling the elongation phase of transcription with P-TEFb. Mol. Cell 23, 297-305 (2006).

3. Wassarman, D. A. \& Steitz, J. A. Structural analyses of the 7SK ribonucleoprotein (RNP), the most abundant human small RNP of unknown function. Mol. Cell. Biol. 11, 3432-3445 (1991).

4. Yang, Z., Zhu, Q., Luo, K. \& Zhou, Q. The 7SK small nuclear RNA inhibits the CDK9/cyclin T1 kinase to control transcription. Nature 414, 317-322 (2001).

5. Zhou, Q. \& Yik, J. H. The Yin and Yang of P-TEFb regulation: implications for human immunodeficiency virus gene expression and global control of cell growth and differentiation. Microbiol. Mol. Biol. Rev. 70, 646-659 (2006).

6. Michels, A. A. et al. Binding of the 7SK snRNA turns the HEXIM1 protein into a P-TEFb (CDK9/cyclin T) inhibitor. EMBO J. 23, 2608-2619 (2004).

7. Zieve, G. \& Penman, S. Small RNA species of the HeLa cell: metabolism and subcellular localization. Cell 8, 19-31 (1976).

8. Missra, A. \& Gilmour, D. S. Interactions between DSIF (DRB sensitivity inducing factor), NELF (negative elongation factor), and the Drosophila RNA polymerase II transcription elongation complex. Proc. Natl Acad. Sci. USA 107, 11301-11306 (2010)

9. Renner, D. B., Yamaguchi, Y., Wada, T., Handa, H. \& Price, D. H. A highly purified RNA polymerase II elongation control system. J. Biol. Chem. 276, 42601-42609 (2001).

10. Wen, Y. \& Shatkin, A. J. Transcription elongation factor hSPT5 stimulates mRNA capping. Genes Dev. 13, 1774-1779 (1999).
11. Yamaguchi, Y., Inukai, N., Narita, T., Wada, T. \& Handa, H. Evidence that negative elongation factor represses transcription elongation through binding to a DRB sensitivity-inducing factor/RNA polymerase II complex and RNA. Mol. Cell. Biol. 22, 2918-2927 (2002).

12. Yik, J. H. et al. Inhibition of P-TEFb (CDK9/Cyclin T) kinase and RNA polymerase II transcription by the coordinated actions of HEXIM1 and 7SK snRNA. Mol. Cell 12, 971-982 (2003).

13. Yik, J. H., Chen, R., Pezda, A. C., Samford, C. S. \& Zhou, Q. A human immunodeficiency virus type 1 Tat-like arginine-rich RNA-binding domain is essential for HEXIM1 to inhibit RNA polymerase II transcription through 7SK snRNA-mediated inactivation of P-TEFb. Mol. Cell. Biol. 24, 5094-5105 (2004).

14. Muniz, L., Egloff, S., Ughy, B., Jady, B. E. \& Kiss, T. Controlling cellular PTEFb activity by the HIV-1 transcriptional transactivator Tat. PLoS Pathog. 6 , e1001152 (2010).

15. He, N. et al. HIV-1 Tat and host AFF4 recruit two transcription elongation factors into a bifunctional complex for coordinated activation of HIV-1 transcription. Mol. Cell 38, 428-438 (2010).

16. Keen, N. J., Churcher, M. J. \& Karn, J. Transfer of Tat and release of TAR RNA during the activation of the human immunodeficiency virus type-1 transcription elongation complex. EMBO J. 16, 5260-5272 (1997).

17. Sobhian, B. et al. HIV-1 Tat assembles a multifunctional transcription elongation complex and stably associates with the 7SK snRNP. Mol. Cell 38, 439-451 (2010)

18. Egloff, S., Van Herreweghe, E. \& Kiss, T. Regulation of polymerase II transcription by 7SK snRNA: two distinct RNA elements direct P-TEFb and HEXIM1 binding. Mol. Cell. Biol. 26, 630-642 (2006).

19. Lebars, I. et al. HEXIM1 targets a repeated GAUC motif in the riboregulator of transcription 7SK and promotes base pair rearrangements. Nucleic Acids Res. 38, 7749-7763 (2010).

20. Calnan, B. J., Tidor, B., Biancalana, S., Hudson, D. \& Frankel, A. D. Argininemediated RNA recognition: the arginine fork. Science 252, 1167-1171 (1991).

21. Durney, M. A. \& D'Souza, V. M. Preformed protein-binding motifs in 7SK snRNA: structural and thermodynamic comparisons with retroviral TAR. J. Mol. Biol. 404, 555-567 (2010).

22. Puglisi, J. D., Chen, L., Blanchard, S. \& Frankel, A. D. Solution structure of a bovine immunodeficiency virus Tat-TAR peptide-RNA complex. Science 270, 1200-1203 (1995).

23. Puglisi, J. D., Tan, R., Calnan, B. J., Frankel, A. D. \& Williamson, J. R. Conformation of the TAR RNA-arginine complex by NMR spectroscopy. Science 257, 76-80 (1992).

24. Pitt, S. W., Majumdar, A., Serganov, A., Patel, D. J. \& Al-Hashimi, H. M. Argininamide binding arrests global motions in HIV-1 TAR RNA: comparison with $\mathrm{Mg} 2+$-induced conformational stabilization. J. Mol. Biol. 338, 7-16 (2004).

25. Tao, J. \& Frankel, A. D. Specific binding of arginine to TAR RNA. Proc. Natl Acad. Sci. USA 89, 2723-2726 (1992)

26. Calnan, B. J., Biancalana, S., Hudson, D. \& Frankel, A. D. Analysis of argininerich peptides from the HIV Tat protein reveals unusual features of RNAprotein recognition. Genes Dev. 5, 201-210 (1991).

27. Xie, B., Invernizzi, C. F., Richard, S. \& Wainberg, M. A. Arginine methylation of the human immunodeficiency virus type 1 Tat protein by PRMT6 negatively affects Tat Interactions with both cyclin T1 and the Tat transactivation region. J. Virol. 81, 4226-4234 (2007).

28. Tao, J. \& Frankel, A. D. Electrostatic interactions modulate the RNA-binding and transactivation specificities of the human immunodeficiency virus and simian immunodeficiency virus Tat proteins. Proc. Natl Acad. Sci. USA 90, 1571-1575 (1993).

29. Aboul-ela, F., Karn, J. \& Varani, G. The structure of the human immunodeficiency virus type-1 TAR RNA reveals principles of RNA recognition by Tat protein. J. Mol. Biol. 253, 313-332 (1995).

30. Long, K. S. \& Crothers, D. M. Characterization of the solution conformations of unbound and Tat peptide-bound forms of HIV-1 TAR RNA. Biochemistry 38, 10059-10069 (1999).

31. Schulze-Gahmen, U. et al. Insights into HIV-1 proviral transcription from integrative structure and dynamics of the Tat:AFF4:P-TEFb:TAR complex Elife 5, e15910 (2016).

32. Puglisi, J. D., Chen, L., Frankel, A. D. \& Williamson, J. R. Role of RNA structure in arginine recognition of TAR RNA. Proc. Natl Acad. Sci. USA 90 3680-3684 (1993)

33. Dethoff, E. A. et al. Characterizing complex dynamics in the transactivation response element apical loop and motional correlations with the bulge by NMR, molecular dynamics, and mutagenesis. Biophys. J. 95, 3906-3915 (2008).

34. Haasnoot, P. C., Bol, J. F. \& Olsthoorn, R. C. A plant virus replication system to assay the formation of RNA pseudotriloop motifs in RNA-protein interactions. Proc. Natl Acad. Sci. USA 100, 12596-12600 (2003). 
35. Kulinski, T. et al. The apical loop of the HIV-1 TAR RNA hairpin is stabilized by a cross-loop base pair. J. Biol. Chem. 278, 38892-38901 (2003).

36. van der Werf, R., Wijmenga, S. S., Heus, H. A. \& Olsthoorn, R. C. Structural and thermodynamic signatures that define pseudotriloop RNA hairpins. $R N A$ 19, 1833-1839 (2013).

37. Brodsky, A. S. \& Williamson, J. R. Solution structure of the HIV-2 TARargininamide complex. J. Mol. Biol. 267, 624-639 (1997).

38. Jayaraman, B. et al. RNA-directed remodeling of the HIV-1 protein Rev orchestrates assembly of the Rev-Rev response element complex. ELife 3, e04120 (2014)

39. Mujtaba, S. et al. Structural basis of lysine-acetylated HIV-1 Tat recognition by PCAF bromodomain. Mol. Cell 9, 575-586 (2002).

40. Pagans, S. et al. The Cellular lysine methyltransferase Set7/9-KMT7 binds HIV-1 TAR RNA, monomethylates the viral transactivator Tat, and enhances HIV transcription. Cell. Host. Microbe 7, 234-244 (2010).

41. Rossenkhan, R. et al. Viral diversity and diversification of major nonstructural genes vif, vpr, vpu, tat exon 1 and rev exon 1 during primary HIV-1 subtype C infection. PLoS ONE 7, e35491 (2012).

42. Krueger, B. J., Varzavand, K., Cooper, J. J. \& Price, D. H. The mechanism of release of P-TEFb and HEXIM1 from the 7SK snRNP by viral and cellular activators includes a conformational change in 7SK. PLoS ONE 5, e12335 (2010).

43. D'Orso, I. et al. Transition step during assembly of HIV Tat:P-TEFb transcription complexes and transfer to TAR RNA. Mol. Cell. Biol. 32, 4780-4793 (2012).

44. Bisgrove, D. A., Mahmoudi, T., Henklein, P. \& Verdin, E. Conserved P-TEFbinteracting domain of BRD4 inhibits HIV transcription. Proc. Natl Acad. Sci. USA 104, 13690-13695 (2007).

45. D'Souza, V. et al. Identification of a high affinity nucleocapsid protein binding element within the Moloney murine leukemia virus Psi-RNA packaging signal: implications for genome recognition. J. Mol. Biol. 314, 217-232 (2001).

46. de Rocquigny, $\mathrm{H}$. et al. First large scale chemical synthesis of the 72 amino acid HIV-1 nucleocapsid protein NCp7 in an active form. Biochem. Biophys. Res. Commun. 180, 1010-1018 (1991).

47. Sharma, K. K. et al. Analysis of the RNA chaperoning activity of the hepatitis $\mathrm{C}$ virus core protein on the conserved 3'X region of the viral genome. Nucleic Acids Res. 40, 2540-2553 (2012).

48. D'Souza, V. \& Summers, M. F. Structural basis for packaging the dimeric genome of Moloney murine leukaemia virus. Nature 431, 586-590 (2004).

49. Guntert, P., Mumenthaler, C. \& Wuthrich, K. Torsion angle dynamics for NMR structure calculation with the new program DYANA. J. Mol. Biol. 273, 283-298 (1997).

50. Tolbert, B. S. et al. Major groove width variations in RNA structures determined by NMR and impact of $13 \mathrm{C}$ residual chemical shift anisotropy and 1H-13C residual dipolar coupling on refinement. J. Biomol. NMR 47, 205-219 (2010).
51. Spriggs, S., Garyu, L., Connor, R. \& Summers, M. F. Potential intra- and intermolecular interactions involving the unique-5' region of the HIV-1 5'UTR. Biochemistry 47, 13064-13073 (2008).

\section{Acknowledgements}

We wish to thank the P50 NIH center grant (GM103297-01) and the Howard Hughes Medical Institute faculty scholar grant (55108516) for funding this project.

\section{Author contributions}

V.V.P., C.S., S.N.K., and V.M.D.'S. conceived and designed experiments. S.N.K. cloned constructs and worked on the initial conditions for NMR and ITC experiments. N.H. and H.d.R. made the specifically labeled protein samples. V.V.P. and C.S. worked on the data analysis for 7SK-SL1. V.V.P. worked on the TAR:Tat data analysis, performed structure calculations, the final ITC experiments, and SAXS analysis. J.L.S., W.C.B., and J.L.M. cloned and prepared the cycT1:Tat:AFF4 complex; V.V.P., C.S., and V.M.D'S. wrote the manuscript.

\section{Additional information}

Supplementary Information accompanies this paper at https://doi.org/10.1038/s41467018-06591-6.

Competing interests: The authors declare no competing interests.

Reprints and permission information is available online at http://npg.nature.com/ reprintsandpermissions/

Publisher's note: Springer Nature remains neutral with regard to jurisdictional claims in published maps and institutional affiliations.

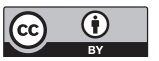

Open Access This article is licensed under a Creative Common Attribution 4.0 International License, which permits use, sharing, adaptation, distribution and reproduction in any medium or format, as long as you give appropriate credit to the original author(s) and the source, provide a link to the Creative Commons license, and indicate if changes were made. The images or other third party material in this article are included in the article's Creative Commons license, unless indicated otherwise in a credit line to the material. If material is not included in the article's Creative Commons license and your intended use is not permitted by statutory regulation or exceeds the permitted use, you will need to obtain permission directly from the copyright holder. To view a copy of this license, visit http://creativecommons.org/ licenses/by/4.0/.

(C) The Author(s) 2018 